\title{
A Bibliography on Finite Element and Related Methods Analysis in Reactor Physics Computations (1971-1997)
}

\section{RECEIVED \\ JAN 201998 \\ OSTI}

David C. Carpenter

Bettis Atomic Power Laboratory

West Mifflin, Pennsylvania 15122-0079

January 1998

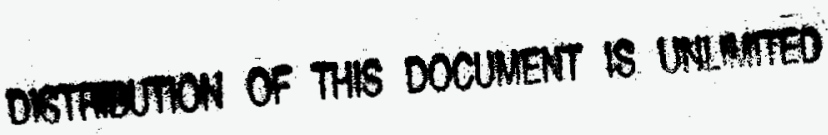

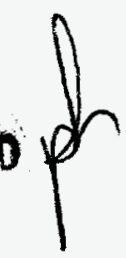

Prepared for the

U.S. Department of Energy

By Westinghouse Electric Corporation

Under Contract No. DE-AC11-93PN38195 


\section{DISCLAIMER}

This report was prepared as an account of work sponsored by an agency of the United States Government. Neither the United States Government nor any agency thereof, nor any of their employees, makes any warranty, express or implied, or assumes any legal liability or responsibility for the accuracy, completeness, or usefulness of any information, apparatus, product, or process disclosed, or represents that its use would not infringe privately owned rights. Reference herein to any specific commercial product, process, or service by trade name, trademark, manufacturer, or otherwise does not necessarily constitute or imply its endorsement, recommendation, or favoring by the United States Government or any agency thereof. The views and opinions of authors expressed herein do not necessarily state or reflect those of the United States Government or any agency thereof. 


\section{DISCLAIMER}

Portions of this document may be illegible electronic image products. Images are produced from the best available original document. 
A Bibliography on the Finite Element and Related Methods Analysis

in Reactor Physics Computations (1971-1997)

\author{
D.C. Carpenter
}

DE-AC11-93PN38195

Printed in the United States of America

Available from the

National Technical Information Service

U.S. Department of Commerce

5285 Port Royal Road

Springfield, Virginia 22151

\title{
NOTE
}

This document is an interim memorandum prepared primarily for internal reference and does not represent a final expression of the opinion of Westinghouse. When this memorandum is distributed externally, it is with the express understanding that Westinghouse makes no representation as to completeness, accuracy, or usability of information contained therein. 


\section{NOTICE}

This report was prepared as an account of work sponsored by the United States Government. Neither the United States, nor the United States Department of Energy, nor any of their employees, nor any of their contractors, subcontractors, or their employees, makes any warranty, express or implied, or assumes any legal liability or responsibility for the accuracy, completeness or usefulness of any information, apparatus, product or process disclosed, or represents that its use would not infringe privately owned rights. 
WAPD-TM-1635

\title{
A Bibliography on Finite Element and Related Methods Analysis in Reactor Physics Computations (1971-1997)
}

\author{
David C. Carpenter \\ Bettis Atomic Power Laboratory \\ West Miffin, PA 15122-0079
}

\section{INTRODUCTION}

This bibliography provides a list of references on finite element and related methods analysis in reactor physics computations. These references have been published in scientific journals, conference proceedings, technical reports, thesis/dissertations and as chapters in reference books from 1971 to the present. Both English and non-English references are included. All references contained in the bibliography are sorted alphabetically by the first author's name and a subsort by date of publication.

The majority of the references relate to reactor physics analysis using the finite element method. Related topics include the boundary element method, the boundary integral method, and the global element method. All aspects of reactor physics computations relating to these methods are included: diffusion theory, deterministic radiation and neutron transport theory, kinetics, fusion research, particle tracking in finite element grids, and applications. For user convenience, many of the listed references have been categorized.

The list of references is not all inclusive. In general, nodal methods were purposely excluded, although a few references do demonstrate characteristics of finite element methodology using nodal methods (usually as a non-conforming element basis). This area could be expanded. The author is aware of several other references (conferences, thesis/dissertations, etc.) that were not able to be independently tracked using available resources and thus were not included in this listing. 


\section{SUBJECT INDEX}

- GENERAL REVIEW [45],[78],[172],[191],[218],[231],[232], [348],[366],[398], [448],[514],[562],[578]

- BOUNDARY ELEMENT METHODS

- Neutron Diffusion Theory [132],[170],[298]-[310],[470],[471],[488], [567], [569]

- Neutron Transport Theory [1],[84],[128]

- FINITE ELEMENT METHODS

- Cross Section Evaluation [532]

- Neutron Diffusion Theory

* Books/Monographs [278]

* Codes/Systems

- DIFGEN [226]

- EDEF [196]

- FEM-BABEL [292],[293]

- FEM2D [212],[520],[521],[554]

- FEMSYN [316],[317]

- FENDER [109],[125],[550],[551]

- FINELM [148],[150],[152],[153],[154], [279],[280],[477],[478]

- JACS [334]

- KONEL [479]

- NEPTUNE [100],[337],[338]

* Curved Boundaries [116]

* Dual/Mixed Forms [136],[137],[257]

* Energy-Dependent Mesh [116],[357],[358],[359],[580]

* Hermite Polynomials [255],[415]

* Hexagonal Geometries [66],[226],[227],[228],[275],[276], [294],[295], [586]

* Hierarchic Shape Functions [116]

* Implementation [92],[115],[269],[476]

* Lumped Source Treatment [468],[469]

* Nodal Methods [25],[30],[151],[164],[165],[186], [187],[271]-[276],[380]

* Parallel Computations [127],[138],[139],[140],[141],[397]

* Response Matrix Method [451],[452],[467],[516]

* Singularities [98],[249],[250],[261],[264]

* Solution Techniques [116],[397],[449],[450] 
* Space-Dependent Cross Sections [115],[339],[340],[371]

* Three-Dimensional Analysis [4],[6],[7],[88],[143], [144],[213], [214],[215],[216],[287],[288],[294], [295],[313],,314],[315],[355],[368], [370], [447],[524],[525]

* Triangular Elements [177],[211]

* Unstructured Mesh [116]

* Vectorization/Supercomputer Computations [296],[346],[529]

* Thesis/Dissertations [79],[98],,[122],[134],[140], [181],,[183],[210], $[214],[249],[357],[540],[603]$

- Neutron Transport Theory

* Adaptive Grids [363]

* Anisotropic Scattering [53],[54],[101],[129],[130],[155], [188],[206], [222],[297],[356],[389],[390],[497], [566],[597]

* Angular Discretization

- Discrete Ordinates [53],[56],[145],,[188],,[189], [219],[233],,237],[272], [277],[320],,[376],[379],[384], [413],[432],[439],[441],[462], [511],,[512], [537],[583],[585]

- Discrete Element Method [408]

- Phase-Space Elements [101],[103],[105],[108],[129], [130],[222], $[382],[404],[405],[420],[421],,[433],[434],[435],[436],[437],[464],[480]$, [482],[556],[594],[595],[596], [597],[599]

- Spherical Harmonics [12],[13],[21],[42],[96], [155],[160],[203],[204], $[205],[208],[229],\{240],[297],[350],[351],[413],[504],[566],[592],[608]$

- Simplified $\mathrm{P}_{N}[188],[189],[413],[442],[443]$

- Walsh Functions [535]

* Books/Monographs [178],[387],[400]

* Coarse Mesh Methods [103],[105],[108],[384],[385],[388]

* Codes/Systems

- ATTILA [585]

- CRONOS [56],[188],[189]

- DANTE [413]

- DFEM [222]

- FEED1/FEED2 [489],[609],[610]

- FELTRAN [15],[29],[36],[185],[297], [490],[497]

- FEMRZ [73],[220]

- FEINT [382]

- FENT [103]

- FESH [96],[97]

- FETONE [229]

- FTRAN [404] 
- MARC [36],[200],[205],[206],[207], [209]

- NIKE/DANTE [442]

- ONETRAN [281]

- RTDENT [549]

- TIMEX [283]

- TRIDENT/TRIPLET [73],[179],[496],[536],[537]

• TRIPAC/EVENT/FELICIT [36],[155],[594],[595],[596], [597]

- TRISM [145],[558]

- ZEPHYR [431],[432],[433],[434], [435],[436]

* Composite Solutions [26],[34],[42]

* Criticality [161]

* Curvilinear Geometries [193],[208],[219],[238],[350],[432], [435],[436], [437],[474],[475],[482],[511],[512], [594],[596],[597]

* Diffusion-Synthetic Acceleration [49],[439],[441],[583]

* Discontinuous Spatial Discretization [22], [42], [50], [117], [145], [219], $[320],[363],[374],[376],[379],[404],[405],[426],[432],[433],[441],[511]$, $[512],[537],[581],[583],[585],[599]$

* Energy-Dependent [53],[155],[219],[297],[389],[390], [489],,[497],[504], [592],[595],[596],[597]

* General Overview [19],[31],[36]

* Hierarchic Shape Functions [465]

* Hybrid Methods

- FEM and Monte Carlo [487]

- FEM and Ray Tracing [336]

* Interface Coupling

- Interface Current Methods [105],[108],[495],[599]

- Response Matrix Method [491],[492],[493],[494],[495]

* Isoparametric Elements [233],[432]

* Nodal Methods [272],[277],[388],[581]

* Parallel Computations [160],[189],[413]

* Petrov-Galerkin [193],,[238]

* Solution Techniques [604],[609]

* Spectral Element Method [593]

* Unstructured Mesh [413],[585]

* Theoretical Development [270],[320],[333],[374],[485],[570]

* Thesis/Dissertations [107],[235],[311],[389],[394],[403], [423],,[492], [565],[590],[601]

* Three-Dimensional Analysis [413],[585]

* Time-Dependent [161],[426] 
* Transport Formulation

- Even/Odd Parity Form [12],,[13],,[16],[17],\{22], [35],[49],[53],,[56], $[103],[105],[108],[155],[160],[188],[189],[229],[240],[297],[327],[382]$, $[384],[413],[420],[421],[439],[482],[489],[497],[504],[535],[556],[566]$, [592],[594],[595],[596],[597], [604],[608]

- First Order Form [21],[22],[203],[205],[219], [222],[233],[404], $[405],[432],[433],[434],[435],[436],[437],[462],[570],[599]$

- Integral Form [356]

* Transverse Buckling [96],[384]

* Treatment of Voids [28],[35],[336]

* Variational Principles [10],[14],[16],[17],[18],[21], [22], [39],[41]

- Kinetics [67],[81],[124],[162],[163],[171], [241],[244],[259],[266],[267],[268], $[290],[291],\{318],[319],[322],[323],[324],[341],[342],[343],[362],[364],[414]$, [456], [499],[500],,[571],[573], [588], [589]

* Thesis/Dissertations [123],[373],[414],[509]

- Other Transport Calculations

* Fusion Analysis [62],[64],[251],[252],[265]

* Well Logging [412],[507]

* Miscellaneous [159],[237],[592]

* Thesis/Dissertations [591]

- Tracking/Ray Tracing in Finite Element Grids [68],[582]

- GLOBAL ELEMENT METHODS

- Neutron Diffusion Theory [113]

- Thesis/Dissertations [114] 


\section{AUTHOR INDEX}

The following lists both primary and secondary authors of the papers contained in the bibliography. In some cases, references use et al. in which case secondary authors are unknown. The listed references appearing in bold face after a particular author indicate a paper in which the individual is listed as the principal author.

Abramov, B.D. [1]

Abu-Shumays, I.K. [2],[3],[82]

Abushady, Y. [4]-[8]

Abuzid, O.A. [42]-[44]

Ackroyd, R.T. [9]-[44],[157],[159],[453], [454],[490],[497],[609]

Adamik, V. [407]

Adams, C.H. [45]

Adams, M.L. [46]-[51],[117],[180],[474],[475], [583]

Aixiang, H. [52]

Akherraz, B. [53],[54],[188]

Al-Bahadili, H. [349]

Alaoui, S. [55]

Albrecht, R.W. [535]

Alcouffe, R. [56]

Alimov, V.I. [57]

Allen, E.J. [58]

Altiparmakov, D.V. [59]-[64],[149]

Alujevic, A. [65]

Ambrosius, H. [523]

Antila, M. [66]

Antolak, A.J. [84]

Arien, B. [67]

Armishaw, M. [68] 
Arnold, C. [69]

Asadzadeh, M. [70]-[72]

Asano, N. [73]

Asaoka, T. [73]

Azekura, K. [74]-[76]

Babuska, I. [77]

Baker, A.R. [78]

Baldasaro, P.F. [79]

Banghua, Y. [587]

Bangqing, X. [80]

Bardiaux, M. [81]

Bareis, E.H. [2],[82]-[84]

Barnett, A. [85]

Barros, R.C. [86]

Basu, T.K. [87]

Bernnat, W. [88]

Bikineeva, S.A. [89]

Birenbaum, R.S. [90]

Birkhold, U. [91]

Biswas, D. [92]

Blomquist, R.N. [93]-[97],[411]

Booker, C.P. [98]

Borisevich, M. [99]

Bosler, G.E. [537]

Bouchard, J. [100]

Bovio, L. [101], [132]

Brebbia, C.A. [300]-[303],[305],[306] 
Briggs, L.L. [102]-[108],[411]

Brinkley Jr., F.W. [496],[536]

Budd, C. [109]

Burda, P. [110]

Calabrese, C.R. [111],[112]

Cali, C.P. [313]

Carpenter, D.C. [113]-[116]

Castrianni, C.L. [117]

Cermak, J. [118]-[120],[517]

Chang, J.H. [353]

Chang, K.S.J. [83]

Changshu, C. [427]

Chauvet, Y. [121]

Cheung, K.Y. [122]

Chichiwa, H. [73]

Chivington, E.P. [123],[124]

Christenson, J.M. [571]-[573]

Chucas, S.J. [125],[551],[552]

Chukhlova, O.P. [126]

Claborn, G.W. [439]

Clark, B.A. [145]

Collart, J.M. [127]

Colombo, V. [101],[128],[129]

Conn, R.W. [252]

Constatinescu, D.A. [83]

Coppa, G.G.M. [101],[128],[129],[130]-[133], [365]

Correia Filho, A. [134],[135] 
Coulomb, F. [136]-[141]

da Silva, C.F. [142]-[144]

Davidson, J.W. [145],[146],[558]

Davierwalla, D.M. [145],[147]-[154],[279],[477]

de Oliveira, C.R.E. [40],[90],[155]-[161], [336],[349],[487],[501],[503], [504],[595]

de Raedt, Ch. [507]

del Valle, E. [162]-[165],[272],[274]-[277]

Dendy Jr., J.E. [440],[441]

Deppe, L.O. [166]-[168]

DeVooght, J. [67],[169]

Dhandhang, M. [170]

Dilber, I. [388]

Disney, R.K. [398]

Dodds, H.L. [555]

Doering, M. [171]

Dorning, J. [172]

Doriath, J.Y. [132]

Du, M.S. [173],[174]

Dubina, Y.V. [175]-[177]

Duderstadt, J.J. [178],[404],[405]

Dudziak, D.J. [146],[179],[558]

Eaton, T.L. [180]

Edwards, D.R. [350],[351]

Ellison, P.G. [181],[182]

Eltawila, F.M. [183]

Estiot, J.C. [184]

Evans, A.M. [185] 
Fedon-Magnaud, C. [53],[54],[56],[127],[136], [137],[186]-[189],[369]

Fedorenko, R.P. [355]

Fen, V.G. [516]

Feng, M. [190]

Ferguson, D.R. [191]

Ferguson, J.M. [192],[193],[238]

Fernandes, A. [194]-[198]

Filio, C. [272]

Filippone, W.L. [199],[200]

Fix, G.J. [201]

Fletcher, J.K. [20],[31],[202]-[211]

Franke, H.P. [212]-[216],[519],[521],[522], [523]

Fremd, R. [217],[524],[525],[527]

Frey, G. [529]

Froehlich, R. [218]

Fu, S.W. [174]

Fujimura, T. [73],[219]-[225],[286]

Gado, J. [226]-[228]

Galliara, J. [11],[229],[556]

Ganapol, B.A. [230]

Gashut, A.M. [43],[44]

Gelbard, E.M. [231],[232]

Gerber, R. [185]

Gerin-Roze, J. [233]-[235]

Germogenova, T.A. [236]

Gerstl, S.A.W. [237]

Gieber, W. [88],[529] 
Goddard, A.J.H. [13],[15],[20],[29],[31],[37], [90],[158],[159],[160],[161], [297],[336], $[349],[487],[490],[608],[609]$

Gorbatov, N.E. [291]

Grant, C.R. [111],[112]

Greenbaum, A. [193],[238]

Grenfell, D.T. [12],[68],[239],[240]

Grossman, L.M. [162],[241]

$\mathrm{Gu}, \mathrm{L} \cdot[242]$

Gulati, S. [201]

Guo, B.L. [243]

Hadek, J. [244]

Hageman, L.A. [3],[245]

Haldy, P.A. [87]

Hammer, P. [458]

Hansen, K.F. [166]-[168],[246]-[248],[312], [321],[323]-[326],[586]

Hardin, D.D. [249],[250]

Harris, D.R. [85]

Harris, J.M. [412]

Hasan, M.Z. [251],[252]

Havranek, M. [253]

Hayashi, M. [254],[446],[545]-[548]

Hebert, A. [255]-[257],[401]

Hendrickson, H.R. [582]

Hennart, J.P. [162],[164],[165],[169],[186], [200],[241],[258]-[276]

Henninger, A.K. [230]

Henry, A.F. [248],[278],[600]

Henry, T.P. [382] 
Higgs, C.E. [145],[279],[280],[477],,[558]

Higuchi, K. [294],[295]

Hill, T.R. [281]-[283],[496]

Hirose, H. [304]

Holloway, J.P. [284],[593]

Honde, D. [184]

Honma, T. [569]

Hongchun, W. [285]

Horikami, K. [219],[220],[286]

Huang, A.X. [287], [288]

Huang, Q.H.. [287],[288]

Ibrahim, M.A. [289]

Ilyushkin, A.I. [236]

Imasaki, M. [290]

Isaev, N.V. [291]

Ise, T. [292],[293]

Ishiguro, M. [294]-[296]

Issa, J.G. [15],[20],[28],[29],[31],[32], [36],[297],,454],[490]

Itagaki, M. [170],[298]-[310]

Ivanov, A.P. [291]

Jaber, A. [311]

Jacquin, J.C. [312]

Jagannathan, V. [313]-[319]

Johnson, C. [320]

Jong, K.K. [602]

Josef, J.A. [439]

Joseph, M.N. [465] 
Kanda, K. [254],[545]-[548]

Kang, C.M. [246],[247],[321]-[326],[499]

Kaper, H.G. [327]-[333],[371],[392]

Kastenburg, W.E. [124]

Katakura, J. [334],[335]

Katsimichas, S. [336],[487]

Katsuragi, S. [73]

Kavenoky, A. [100],[337]-[347]

Kavkler, M. [65]

Kawamura, R. [447]

Kellogg, R.B. [77],[348]

Khaddaj, S.A. [349]

Khouaja, H. [350],[351]

Kikuchi, F. [352]

Kim, C.H. [353]

Kim, D.H. [353]

Kim, J.K. [354],[445]

Kim, Y.I. [354]

Klimov, A.D. [355]

Kohut, P. [356]

Komoriya, H. [357]-[359],[580]

Kornilov, A.I. [360]

Kurchenkova, G.I. [361]

Kuz'miniv, V.V. [362]

Kwankam, S.Y. [465]

Lang, J. [363]

Langenbuch, S. [364] 
Lapenta, G. [101],[129],[130],[131],[365]

Larsen, E.W. [443],[583]

Lathrop, K.D. [366],[367],[496]

Lautard, J.J. [53],[54],[56],[127],[186], [188],[339]-[347],[368]-[370], [458]

Leaf, G.K. [327]-[333],[371],[392]

Lebedev, V.I. [400]

Lecot, C. [372]

Lee, L.W. [373]

Lee, M.J. [411]

Lelek, V. [118],[120]

Lesaint, P. [233],[374]-[380]

Lewis, E.E. [93],[95],[96],,[97], [102]-[106],[108],[182], [381]-[388],[411],,418]-[422], $[472],[538],[539],[541],[542],[604],[605]$

Lianxiang, F. [427]

Lillie, R.A. [389]-[391]

Lindeman, A. [327]-[333],[371],[392]

Liu, C.F. [173]

Lorence Jr., L.J. [393]-[395],[405],[495]

Loubiere, S. [369]

Luskin, M. [395]

Lysne, P.C. [412]

Maeder, C. [151]

Maiorino, J.R. [194]-[196],,[198],[396],[466]

Malambu, E. [274]

Majumbar, A. [397]

Mallett, R.H. [398]

Manuel, A. [342] 
Manteuffel, T. [399]

Marchuk, G.I. [400]

Markovic, M.I. [62],[64]

Marleau, G. [401]

Marr, D.K. [145]

Martin, J.G. [263],[265]

Martin, W.R. [46],[51],[178],[393],[395], [397],[402]-[405],[451],[452], [467],,491], [493],[494],[495]

Mastrangelo, V. [406]

Matejovic, P. [407]

Mathews, K.A. [408],[409]

Mathonniere, G. [410]

Matsumura, M. [221]-[223]

Maurer, W. [364]

Mayer, P.R. [529]

McCormick, N.J. [514]

McCormick, S. [399]

McCoy, D.R. [411]

McGhee, J.M. [413],[439],[442],[443]

McDaniel, P.J. [412],[592]

Meade, D. [162],[164],[165],[241],[414],[415]

Mederbel, Y. [416]

Memmert, G. [588]

Mihanti, P.K. [455]

Mika, J. [417]

Miller, G.D. [579]

Miller, P.C. [68] 
Miller Jr., W.F. [102],[103],[381],[382],[387], [418]-[425],[459],[460],[536], [537],[604]

Ming-Sheng, D. [426],[427]

Mirza, A.M. [42]

Misfeldt, I. [428]-[430]

Miya, K. [569]

Miyasaka, S. [73]

Miyoshi, Y. [304]

Mizuta, H. [73]

Montagnini, B. [132]

Mordant, M. [431]-[437]

Moreau, F. [370]

Morel, J.E. [85],[399],[413],[438]-[443],[459], [460],[584]

Mund, E.H. [67],[169],[261],[264],[274]-[276], [599]

Mus, M. [444]

Na, B.C. [445]

Naito, Y. [446],[447]

Najzer, M. [567]

Nakahara, Y. [219]-[223],[286],[292],[448]

Nakamura, H. [73]

Nakamura, S. [449],[450]

Nakata, H. [451],[452]

Nanneh, M.M. [32],[33],[39],[453],[454]

Naoum, R.S. [455]

Narita, M. [170],[488]

Nguyen, D.H. [456]

Nicolas, A. [457]

Nisan, S. [458] 
Noh, T. [425],[459],[460]

O'Dell, R.D. [461]

Ohnishi, T. [73],[219],[220],[286],[449], [450],[462]-[464]

Oliveira, S. [399]

Olvey, L.A. [439]

Onana, A. [465]

Ono, S. [466]

Ooki, M. [290]

Oukebdane, A. [467]

Ozgener, B. $[468]-[471]$

Ozgener, H.A. [385],[468],[470],[471], [472],[473]

Pain, C.C. [160],[161]

Palmer, T.S. [474],[475]

Palmiotti, G. [184]

Parish, T.A. [113],[115]

Parsons, D.K. [585]

Pautz, S. [585]

Pelloni, S. [146],[149],[476]-[478]

Petrovicj, I. [479]

Pflieger, H. [525]

Pinchedez, K. [189]

Pitkaranta, J. [320],[480]-[485]

Pohlen, E. [486]

Pomraning, G.C. [560]

Popykin, A.I. [360]

Pourzand, M. [533]

Price, R.A. [487] 
Purwadi, M.D. [488]

Quah, C.S. [20],[489],[490]

Quinhuai, H. [52]

Ram, K.S. [92]

Rao, S.S. [92]

Rastogi, B.P. [314]

Rathkopf, J.A. [491]-[495]

Ravetto, P. [101],[128],[129],[130],[131], [132],[133],[365]

Raviart, P.A. [374],[378]

Real, E. [200]

Reed, W.H. [283],[496]

Reuss, P. [100],[341]

Ritterbusch, S.E. [500]

Riyait, N.S. [15],[28],[29],[32],[35],[297], [454],[497]

Robeau, D. [342]

Roberts, R.M. [413]

Robinson, J.C. [390],[391],[563],[564],[566]

Robinson, M.A. [498]

Roderick, N. [592]

Rohan, P.E. [499],[500]

Rossow, E.C. [418]-[421],[538],[539],[541], [542]

Rothenstein, W. [501]-[505]

Rousselet, B. [506]

Roy, R. [401]

Roybal, J.A. [230]

Ruan, D. [507]

Ruhle, R. [508] 
Rydin, R.A. [498]

Sahashi, N. [308],[309]

Sainz, E. [269]

Salehi, M.A. [509]

Salinas, D. [456]

Salvatores, M. [184]

Samba, G. [510]-[512]

Sanchez, C.A. [513]

Sanchez, J. [263],[265]

Sanchez, R. [54],[514]

Sapper, E. [213],[515],[522],[523]

Sarychev, V.A. [516]

Schenter, R.E. [532]

Schmid, J. [118],[119],[517],[518]

Schmidt, F.A.R. [69],[88],[91],[151], [212],[213],[228],[519]-[531], [534]

Schmittroth, F. [532]

Schofield, S.L. [533]

Schwab, B. [534]

Seed, T.J. [145],[535],[536],[537]

Semenza, L.A. [538]-[542]

Shang-Wu, F. [426],[543],[544]

Shen, L.J. [243]

Shibata, T. [254],[545]-[548]

Shiroya, S. [254],[545]-[548]

Shober, R.A. [499]

Shuli, C. [549]

Shuttleworth, E. [68],[109],[550]-[552] 
Siebertz, A. [67]

Silvennoinen, P. [66],[480],[481],[482],[553]

Silver, E.G. [554]

Sjoestrand, N.G. [80]

Skerget, L. [567]

Slesarev, I.S. [175],[176],[291],[362]

Smith, P.W. [250]

Sofu, T. [555]

Soo, D.S. [602]

Splawski, B.A. [16],[18],[556]

Srinivasan, L. [557]

Stepanek, J. [145],[146],[179],[461],[558]

Stott, G.E. [297]

Strakhovskaya, J.G. [355]

Suk, S.D. [354]

Sumini, M. [128]

Suslov, I.R. [559]

Swanson, C.D. [386]

Szilzard, R.H. [560]

Tanaka, S. [569]

Tang, Y.R. [287],[288]

Tiekai, F. [427]

Tinka, I. [561],[562]

Tokuno, Y. [447]

Tomlinson, E.T. [563]-[566]

Trkov, A. [567]

Trubey, D.K. [582] 
Tsapelkin, E.S. [568]

Tsoulfanidis, N. [351]

Tsuchimoto, M. [569]

Tsuji, M. [170],[488]

Tsuruta, S. [446],[447]

Tsutsui, T. [73],[219],[220]

Tu, Z.G. [287],[288]

Tuominen, J. [553]

Ukai, S. [570]

Umpleby, A.P. [90],[161]

Utku, H. [571]-[573]

Vacek, J. [574],[575]

Vanicek, J. [120]

Varda, G. [132]

Verwaerde, D. [380],[576],[577]

Vesely, V. [118]

Vieira, W.J. [396]

Villegas, M. [269]

Vondy, D.R. [563],[564]

Wachspress, E.L. [555]

Wagner, M.R. [461],[523],[578]

Wagner, S.G. [499],[500]

Wakoff, G.I. [201]

Walter, A. [363]

Walters, W.F. [358],[359],[442],[579]-[581], [584]

Wang, Y. [242]

Ward Jr., J.T. [582] 
Wareing, T.A. [440],[441],[583]-[585]

Watmough, M.H. [15],[29],[185]

Wei, T.Y.C. [586]

Weimin, L. [587]

Weisner, J. [119]

Wepler, J. [588],[589]

Werner, W. [364]

Wheaton, R.C. [590]

Wick, R.S. [250]

Williams, M.M.R. [11],[16],[20],[23],[31], [229],[594],[598]

Wills, E.E. [591],[592]

Wilson, W.E. [26],[34]

Winstanley, D.D. [185]

Woerner, D. [524],[525]

Wojtowicz, G. [284],[593]

Wood, J. [20],[31],[157],[349], [594]-[598]

Wu, G.J. [188]

Xing, H. [599]

Yamazaki, T. [292]

Yang, G. [399]

Yang, S. [600]

Yehnert, C.E. [405],[601]

Yong, I.L. [602]

Yoo, K.J. [603]

Yu, S. [242]

Yuan, Y.C. [604]-[606]

Yulan, L. [427] 
Yuren, T. [52]

Zardecki, A. [237]

Zhang, F. [507]

Zheng, J.D. [607]

Zhongsheng, X. [285],[587]

Zhuguo, T. [52]

Ziver, A.K. [13],[16],[40],[556],[608]-[610]

Zong, W. [242]

Zukeran, A. [73] 
WAPD-TM-1635

\section{REFERENCES}

[1] B.D. Abramov, "Method of Boundary Integral Equations in Transport Theory," FEI-1264, 1982, Fiziko-Energeticheskii Inst., Obninsk, USSR

[2] I.K. Abu-Shumays and E.H. Bareis, "Singular Elements in Variational and Finite Element Transport Calculations," Trans. Am. Nucl. Soc., 17, 236-237 (1973)

[3] I.K. Abu-Shumays and L.A. Hageman, "Development and Comparison of Practical Discretization Methods for the Neutron Diffusion Equation Over General Quadrilateral Partitions," Proc. Conf. Comput. Meth. in Nucl. Eng., April 15-17, 1975, Charleston, SC, Vol 1, pp I.117-I.165

[4] Y. Abushady, "A Synthesis Finite Element Method for Three-Dimensional Reactor Calculations," Trans. Am. Nucl. Soc., 32, 304-305 (1979)

[5] Y. Abushady, "Synthesis-Finite-Element Method for Two-Dimensional Reactor Calculations," Atomkernenergie, 34, 283-287 (1979)

[6] Y. Abushady, "Three-Dimensional Diffusion Burnup Calculations a One-Dimensional Synthesis Finite Element Method," Trans. Am. Nucl. Soc., 34, 302-303 (1980)

[7] Y. Abushady, "A One-Dimensional Synthesis Finite Element Method for ThreeDimensional Reactor Calculations," Atomkernenerg./Kerntech., 37, 183-187 (1981)

[8] Y. Abushady, "A Finite Element Method for R,Z Core Calculations," Atomkernenerg./Kerntech, 46, 243-247 (1985)

[9] R.T. Ackroyd, "Finite Element Method for Neutron Transport. Part IV. A Variational Principle Giving an Upper Bound for the Lowest Eigenvalue of the Boltzamnn Equation," ND-R-93(R), February 1978, UKAEA, Risley, UK

[10] R.T. Ackroyd, "A Finite Element Method for Neutron Tranport - I. Some Theoretical Considerations," Ann. Nucl. Energy, 5, 75-94 (1978)

[11] R.T. Ackroyd, J. Galliara and M.M.R. Williams, "Finite Element Technique for the Even-Parity Neutron Transport Equation," The Mathematics of Finite Elements and Applications III, MAFELAP 1978, Uxbridge, UK, April 1978, J.R. Whiteman (Ed.), Academic Press, (1978), pp 349-357

[12] R.T. Ackroyd and D.T. Grenfell, "A Finite Element Method for Neutron Transport - III. Two-Dimensional One-Group Test Problems," Ann. Nucl. Energy, 6, 563-577 (1979)

[13] R.T. Ackroyd, A.K. Ziver and A.J.H. Goddard, "A Finite Element Method for Neutron Transport. Part IV: A Comparison of Some Finite Element Solutions of Two Group Benchmark Problems with Conventional Solutions," Ann. Nucl. Energy, 7, 335-349 (1980) 
[14] R.T. Ackroyd, "The Why and How of Finite Elements," Proc. Int. Seminar on Finite Element Methods in Radiation Physics, April 23-24, 1981, London Univ., London, UK, published in Ann. Nucl. Energy, 8, 539-566 (1981)

[15] R.T. Ackroyd, A.J.H. Goddard, J.G. Issa, N.S. Riyait and M.H. Watmough, "The Finite Element Transport Code FELTRAN: Its Structure and Benchmarking," Int. Topl. Mtg. on Advances in Reactor Physics, Mathematics and Computation, April 27-30, 1987, Paris, France, Vol 3, pp 1227-1239

[16] R.T. Ackroyd, B.A. Splawski, M.M.R. Williams and A.K. Ziver, "Miscellaneous Remarks on Choice of Moments, Moment Reduction, Local- And Global-Error Bounds," Proc. Int. Seminar on Finite Element Methods in Radiation Physics, April 23-24, 1981, London Univ., London, UK, published in Ann. Nucl. Energy, 8, 717-720 (1981)

[17] R.T. Ackroyd, "Completely Boundary-Free Minimum and Maximum Principles for Neutron Transport and Their Least-Squares and Galerkin Equivalents," Ann. Nucl. Energy, 9, 95-124 (1982)

[18] R.T. Ackroyd and B.A. Splawski, "A Finite Element Method for Neutron Transport - VI. Upper and Lower Bounds for Local Characteristics of Solutions," Ann. Nucl. Energy, 9, 315-330 (1982)

[19] R.T. Ackroyd, "Hilbert Space Method for the Numerical Solution of Reactor Physics Problems," presented at Conf. on the Neutron and Its Applications, September 13-17, 1982, Cambridge, UK, published in Inst. Phys. Conf. Series 64, Section 5, 377-382 (1983)

[20] R.T. Ackroyd, J.K. Fletcher, A.J.H. Goddard, J.G. Issa, C.S. Quah, M.M.R. Williams and J. Wood, "Some Benchmark Shielding Problems Solved by the Finite Element Method," Proc. 6th Int. Conf. on Radiation Shielding, Tokyo, Japan, May 16, 1983, pp 312-320

[21] R.T. Ackroyd, "Least-Squares Derivation of Extremum and Weighted-Residual Methods for Equations of Reactor Physics - I. The First-Order Boltzmann Equation and a First-Order Initial-Value Equation," Ann. Nucl. Energy, 10, 65-99 (1983)

[22] R.T. Ackroyd, "A Finite Element Method for Neutron Transport - VII. Completely Boundary-Free Maximum Principle for the First-Order Boltzmann Equation," Ann. Nucl. Energy, 10, 243-261 (1983)

[23] R.T. Ackroyd and M.M.R .Williams, "An Extended Variational Principle for an Albedo Boundary Condition," Ann. Nucl. Energy, 11, 269-273 (1984)

[24] R.T. Ackroyd, "Least Squares Formulation of Extremum Principles and Weighted Residual Methods Used in Finite Element Codes for Solving the Boltzman Equation for Neutron Transport," The Mathematics of Finite Elements and Applica- 
tions - MAFELAP V, J.R. Whiteman (ed.), Academic Press, London, (1985), pp $571-585$

[25] R.T. Ackroyd, "A Finite Element Method for Diffusion Theory Embracing Nodal and Difference Methods," Proc. Int. Seminar on Finite Element and Allied Methods for Reactor Physics and Shielding Calculations, September 18-20, 1985, London, England, published in Prog. Nucl. Energy, 18, 7-20 (1986)

[26] R.T. Ackroyd and W.E. Wilson, "Discontinuous Finite Elements for Neutron Transport Analysis," Proc. Int. Seminar on Finite Element and Allied Methods for Reactor Physics and Shielding Calculations, September 18-20, 1985, London, England, published in Prog. Nucl. Energy, 18, 39-44 (1986)

[27] R.T. Ackroyd, "Generalized Least Squares as a Generator of Variational Principles and Weighted Residual Methods for FEM Transport Methods," Proc. Int. Seminar on Finite Element and Allied Methods for Reactor Physics and Shielding Calculations, September 18-20, 1985, London, England, published in Prog. Nucl. Energy, 18, 45-62 (1986)

[28] R.T. Ackroyd, J.G. Issa and N.S. Riyait, "Treatment of Voids in Finite Element Transport Methods," Proc. Int. Seminar on Finite Element and Allied Methods for Reactor Physics and Shielding Calculations, September 18-20, 1985, London, England, published in Prog. Nucl. Energy, 18, 85-89 (1986)

[29] R.T. Ackroyd, A.J.H. Goddard, J.G. Issa, N.S. Riyait and M.H. Watmough, "The Finite Element Transport Code FELTRAN: Its Structure and Benchmarking" Int. Topl. Mtg. on Advances in Reactor Physics, Mathematics and Computation, April 27-30, 1987, Paris, France, Vol 3, pp 1227-1239

[30] R.T. Ackroyd, "A Least Squares Principle Unifying Finite Element, Finite Difference and Nodal Methods for Diffusion Theory," Prog. Nucl. Energy, 19, 137-172 (1987)

[31] R.T. Ackroyd, J.K. Fletcher, A.J.H. Goddard, J.G. Issa, M.M.R. Williams and J.Wood, "Some Recent Developments in Finite Element Methods for Neutron Transport," Adv. Nucl. Sci. Technol., 19, 381-483 (1987)

[32] R.T. Ackroyd, J.G. Issa, M.M. Nanneh and N.S. Riyait, "Projection and Conservation Methods for Neutron Transport," The Mathematics of Finite Elements and Applications - MAFELAP VI, J.R. Whiteman (ed.), Academic Press, London, (1987), p 451-462

[33] R.T. Ackroyd and M.M. Nanneh, "Upper and Lower Bounds for Disadvantage Factors as a Test of an Algorithm Used in a Synthesis Method," Ann. Nucl. Energy, 15, 241-259 (1988)

[34] R.T. Ackroyd and W.E. Wilson, "Composite Finite Element Solutions for Neutron Transport," Ann. Nucl. Energy, 15, 397-419 (1988) 
[35] R.T. Ackroyd and N.S. Riyait, "Iteration and Extrapolation Methods for the Approximate Solution of the Even-Parity Transport Equation for System with Voids," Ann. Nucl. Energy, 16, 1-32 (1989)

[36] R.T. Ackroyd and J.G. Issa, "Commercial Exploitation of Finite Element Codes for Neutron Transport," Trans. Am. Nucl. Soc., 60, 335-336 (1989)

[37] R.T. Ackroyd and A.J.H. Goddard, "Evolution of a Finite Element Method for Neutron Transport," The Mathematics of Finite Elements and Applications. VII (MAFELAP 1990), J.R. Whiteman (ed.), Academic Press, London, (1991), pp $151-161$

[38] R.T. Ackroyd, "Foundations of Finite Element to Neutron Transport," 3rd Int. Seminar on Finite Element and Allied Methods in Radiation Transport: Shielding, Reactor Physics, and Geophysics Applications, April 19-20, 1990, Imperial College, London, UK

[39] R.T. Ackroyd and M.M. Nanneh, "Hybrid Variational Principles and Synthesis Method for Finite Element Neutron Transport Calculations," Ann. Nucl. Energy, 17, 603-634 (1990)

[40] R.T. Ackroyd, C.R.E. de Oliveira and A.K. Ziver, "Sagmented Solution Strategies for FEM Solutions," 3rd Int. Seminar on Finite Element and Allied Methods in Radiation Transport: Shielding, Reactor Physics, and Geophysics Applications, April 19-20, 1990, Imperial College, London, UK

[41] R.T. Ackroyd, "Finite Element Methods for Neutron Transport Based on Maximum and Minimum Principles for Discontinuous Trial Functions," Ann. Nucl. Energy, 19, 565-592 (1992)

[42] R.T. Ackroyd, O.A. Abuzid and A.M. Mirza "Discontinuous Finite Element Solutions for Neutron Transport in X-Y Geometry," Ann. Nucl. Energy, 22, 181-201 (1995)

[43] R.T. Ackroyd, A.M. Gashut and O.A. Abuzid, "Discontinuous Variational Solutions for the Neutron Diffusion Equation," Ann. Nucl. Energy, 23, 1289-1300 (1996)

[44] R.T. Ackroyd, A.M. Gashut and O.A. Abuzid, "Synthesis of Conservative Discontinuous Solutions for Diffusion Theory," Ann. Nucl. Energy, 23, 1381-1399 (1996)

[45] C.H. Adams, "Current Trends in Methods for Neutron Diffusion Calculations," Nucl. Sci. Eng., 64, 552-562 (1977)

[46] M.L. Adams and W.R. Martin, "A Method for Synthetically Accelerating Discontinuous Finite Element Transport Calculations," Trans. Am. Nucl. Soc., 54, $159-160(1987)$ 
[47] M.L. Adams, "Asymptotic Solutions of Three-Dimensional Finite-Element Transport Problems in Optically Thick, Diffusive Regimes," 3rd Int. Seminar on Finite Element and Allied Methods in Radiation Transport: Shielding, Reactor Physics, and Geophysics Applications, April 19-20, 1990, Imperial College, London, UK

[48] M.L. Adams, "Even-Parity Finite-Element Transport Methods in the Diffusion Limit," 3rd Int. Sem. Finite Element and Allied Meth. in Rad. Transport: Shielding, Reactor Physics and Geophysics Appl., April 19-20, 1990, London, UK, published in Prog. Nucl. Energy, 25, 159-198 (1991)

[49] M.L. Adams, "Even- and Odd-Parity Finite-Element Transport Solutions in the Thick Diffusion Limit," Proc. Int. Topl. Mtg. Advances in Math.; Comp., and Reactor Phys., April 28-May 2, 1991, Pittsburgh, PA, Vol 5, pp 21.1 2-1 - 2-12

[50] M.L. Adams, "Discontinuous Finite-Element Transport Solutions in the Thick Diffusion Limit in Cartesian Geometry," Proc. Int. Topl. Mtg. Advances in Math., Comp., and Reactor Phys., April 28-May 2, 1991, Pittsburgh, PA, Vol 5, pp 21.1 3-1 - 3-15

[51] M.L. Adams and W.R. Martin, "Diffusion Synthetic Acceleration of Discontinuous Finite Element Transport Iterations," Nucl. Sci. Eng., 111, 145-167 (1992)

[52] H. Aixiang, H. Qinghuai, T. Yuren and T. Zhuguo, "Finite Element Analysis of Neutron Diffusion Equations and Reactor Core Fuel Management," CNIC-00195, April 1988, China Nuclear Information Centre, Beiging, China (in Chinese)

[53] B. Akherraz, C. Fedon-Magnaud and J.J. Lautard, "An Anisotropic Scattering Treatment for the Even Parity Transport Equation," Joint Int. Conf. Mathematical Methods and Supercomputing in Nuclear Applications, $M B C+S N A$ '93, April 19-23, 1993, Karlsruhe, Germany, Vol 2, pp 467-475

[54] B. Akherraz, C. Fedon-Magnaud, J.J. Lautard; and R. Sanchez, "Anisotropic Scattering Treatment for the Neutron Transport Equation with Primal Finite Elements," Nucl. Sci. Eng., 120, 187-198 (1995)

[55] S. Alaoui, "Resolution of the Two-Energy-Group Diffusion Equation in Two Dimensions," Trans. Canadian Nuclear Assoc. Student Conf., March 12, 1982, Montreal, Quebec, Canada, pp 124-128 (in French)

[56] R. Alcouffe, C. Fedon-Magnaud and J.J. Lautard, "A Three Dimensional Method for the Solution of the Even Parity Transport Equation Using Finite Elements," Int. Topl. Mtg. Advances in Math., Comp., and Reactor Phys., April 28-May 2, 1991, Pittsburgh, PA, Vol 4, pp 17.1 3-1 - 17.1 3-10

[57] V.I. Alimov, "Application of the Ritz Method in Problems of Neutron Transport Theory," Proc. 4th All-Union Conf. Variational-Difference Methods in Mathematical Physics, 1980, Novosibirsk, USSR, pp 16-19 
[58] E.J. Allen, "A Finite Element Approach for Treating the Energy Variable in the Numerical Solution of the Neutron Transport Equation," Transp. Theory Stat. Phys., 15, 449-478 (1986)

[59] D.V. Altiparmakov, "Some Improvements in Finite-Element Method Applied to Neutron-Diffusion Calculations," EIR-429, May 1981, Eidgenoessisches Inst. fuer Reaktorforschung, Wuerenlingen, Switzerland

[60] D.V. Altiparmakov, "Nested Element Method in Multidimensional Neutron Diffusion Calculations," Int. Conf. on Numerical Methods in Nucl. Eng., September 6-9, 1983, Montreal, Canada, Vol 1, pp 327-346

[61] D.V. Altiparmakov, "On the Trial Functions in Nested Element Method," Proc. Int. Mtg. on Advances in Nucl. Eng. Comput. Methods, April 9-11, 1985, Knoxville, TN, Vol 2, pp 567-580

[62] D.V. Altiparmakov and M.I. Markovic, "A Method for Tokamak Neutronics Calculations," Proc. 33rd Conf. Electronics, Telecommunications, Automation and Nucl. Eng., June 12-17, 1989, Novi Sad, Yugoslavia, pp IX.11 - IX.18 (In SerboCroat)

[63] D.V. Altiparmakov, "R-Function Solution of the Neutron Transport Equation," Trans. Am. Nucl. Soc., 59, 160-162 (1989)

[64] D.V. Altiparmakov and M.I. Markovic, "An R-Function Method for Neutron Transport Calculations of Toroidal Systems," Trans. Am. Nucl. Soc., 62, 280$282(1990)$

[65] A. Alujevic and M. Kavkler, "Neutron Flux Computation by a Finite Element Code," Atomkernenergie, 31, 84-86 (1978)

[66] M. Antila and P. Silvennoinen, "Coarse Mesh Finite Element Analysis of the Core Power Distribution in Hexagonal Geometry," Kernenergie, 19, 218-220 (1976)

[67] B. Arien, A. Siebertz, J. DeVooght and E. Mund, "CASSANDRE: A Two-Dimensional Multigroup Diffusion Code for Reactor Transients Analysis," BLG-571, September 1984, Centre d'Etude de 'Energie Nucleaire, Mol, Belgium

[68] M. Armishaw, D.T. Grenfell, P.C. Miller and E. Shuttleworth, "The Development of a Monte Carlo Code for the Solution of Generalized-Geometry Problems by Tracking in a Finite Element Mesh," Ann. Nucl. Energy, 8, 699-707 (1981)

[69] C. Arnold and F. Schmidt, "Benchmark Calculations for a Fast Sodium-Cooled Breeder Reactor According to the Method of Finite Elements," IKE-4-87, February 1979, Inst. fuer Kernenergetik und Energiesysteme, FRG (in German)

[70] M. Asadzadeh, "Analysis of a Fully Discrete Scheme for the Neutron Transport in Cylindrical Geometry," CTH-MATH-1984-1, 1984, Chalmers Univ. Tech., Goeteborg, Sweden 
[71] M. Asadzadeh, "Analysis of a Fully Discrete Scheme for Neutron Transport in Two-Dimensional Geometry," SIAM J. Num. Anal., 23, 543-561 (1986)

[72] M. Asadzadeh, "Numerical Approximations for Isotropic Neutron Transport Equation," Proc. Discrete Kinetic Theory, Lattice Gas Dynamics and Foundations of Hydrodynamics, 1988, Torino, pp 6-16

[73] T. Asaoka, et al., "Benchmark tests of Radiation Transport Computer Codes for Reactor Core and Shield Calculations," J. Nucl. Sci. Technol., 15, 56-71 (1978)

[74] K. Azekura, "A New Finite-Element Solution Technique of Neutron Diffusion Equations," Trans. Am. Nucl. Soc., 30, 240-241 (1978)

[75] K. Azekura, "New Finite Element Solution Technique for Neutron Diffusion Equations," J. Nucl. Sci. Technol., 17, 89-97 (1980)

[76] K. Azekura, "Generalization of New Finite Element Method Using 'Imaginary' Nodal Points," J. Nucl. Sci. Technol., 17, 900-907 (1980)

[77] I. Babuska and R.B. Kellogg, "Mathematical and Computational Problems in Reactor Calculations," Proc. Mathematical Models and Computational Techniques for Analysis of Nuclear Systems, April 9-11, 1973, Ann Arbor, MI, pp VII.67VII.94

[78] A.R. Baker, "Mesh-Size Errors in Diffusion-Theory Calculations Using FiniteDifference and Finite-Element Methods," ND-R-755(R), July 1982, UKAEA, Risley Nuclear Power Development Establishment

[79] P.F. Baldasaro, Finite Element Solution of the Multi-Group Neutron Diffusion Equation Applied to the Hypothetical Core Disruptive Accident, PhD Thesis, Rensselaer Poltechnic Inst., Troy, NY, 1980

[80] X. Bangqing and N.G. Sjoestrand, "Finite Element Method and Spline Finite Element Method," CTH-RF-63, February 1989, Chalmers Univ. Tech., Goeteborg, Sweden

[81] M. Bardiaux, et al., "CASSANDRE: A 2D Multigroup Diffusion Benchmark Code for Fast Reactors Power Excursion Analysis," Mtg. Nucl. Power Reactor Safety, October 16, 1978, Brussels, Belgium

[82] E. H. Bareiss and I.K. Abu-Shumays, "Finite Elements in Neutron Transport Theory," C00-2280-1, May 1973, Northwestern Univ., Evanston, IL

[83] E.H. Bareiss, K.S.J. Chang and D.A. Constatinescu, "Exact and Approximate Interior Corner Problem in Neutron Diffusion by Integral Transform Methods," C00-2280-28, September 1976, Northwestern Univ., Evanston, IL

[84] E.H. Bareiss and A.J. Antolak, "Solution of the Transport Equation by the BIF Method," Prog. Nucl. Energy, 8, 295-307 (1981) 
[85] A. Barnett, J.E. Morel, D.R. Harris, "A Multigrid Acceleration Method for the One-Dimensional $S_{N}$ Equations with Anisotropic Scattering," Nucl. Sci. Eng., 102, 1-21 (1989)

[86] R.C. Barros, "On the Equivalence of Discontinuous Finite Element Methods and Discrete Ordinates Methods for the Angular Discretization of the Linearized Boltzmann Equation in Slab Geometry," Ann. Nucl. Energy, 24, 1013-1026 (1997)

[87] T.K. Basu and P.A. Haldy "Preliminary Studies for Uranium-233 Breeding Measurements in Thorium Oxide Assembly at the LOTUS Facility," Proc. 5th Int. Conf. Emerging Nuclear Energy Systems 1989, ICENES '89, July 3-6, 1989, Karlsruhe, West Germany, pp 219-223

[88] W. Bernnat, F.A.R. Schmidt and W. Gieber, "Treatment of Cavities in ThreeDimensional Diffusion Calculations Based on the Finite Element Method," Int. Conf. Physics of Reactors: Operation, Design and Computation, Physor 90, April 23-27, 1990, Marseille, France, Vol 3, pp PII.1 - PII.9

[89] S.A. Bikineeva et al., "Uskorenie Skhodimosti Iteratsionnogo Protsessa Polinomami Chebysheva pri Reshenii Uravneniya Perenosa Nejtronov Metodem Galerkina," NIIAR-P-17(351), 1978, Nauchno-Issledovatel'skij Inst. Atomnykh Reaktorov, Dimitrivgrad, USSR

[90] R.S. Birenbaum, C.R.E. de Oliveira, A.P. Umpleby and A.J.H. Goddard, "Parallel Solution of Multidimensional Finite Element-Spherical Harmonics Radiation Transport Equations," Int. Conf. Reactor Physics and Reactor Computations, January 23-26, 1994, Tel Aviv, Israel, pp 415-423

[91] U. Birkhold and F.A.R. Schmidt, "Calculation of a Pressurized-Water Reactor and a Boiling-Water Reactor Fuel Rod Cluster Using the Finite Element Method with First Order Triangular Elements," IKE-4-52e, July 1975, Inst. fuer Kernenergetik und Energiesysteme, FRG (in German)

[92] D. Biswas, K.S. Ram and S.S. Rao, "Application of 'Natural Coordinate System' in the Finite Element Solution of Multigroup Neutron Diffusion Equation," Ann. Nucl. Energy, 3, 465-469 (1976)

[93] R.N. Blomquist and E.E. Lewis, "Complex Trial Functions in the Even-Parity Transport Equation," Trans. Am. Nucl. Soc., 28, 256-257 (1978)

[94] R.N. Blomquist, Buckled Spherical Harmonics Solutions of Neutron Transport Problems, PhD Dissertation, Northwestern Univ., Evanston, IL, 1979

[95] R.N. Blomquist and E.E. Lewis, "Buckled Spherical Harmonics Solutions of Neutron Transport Problems," NUREG/CR-0823, April 1979, Northwestern Univ., Evanston, IL 
[96] R.N. Blomquist and E.E. Lewis, "A Rigorous Treatment of Transverse Buckling Effects in Two-Dimensional Neutron Transport Computations," Nucl. Sci. Eng., 73, 125-139 (1980)

[97] R.N. Blomquist and E.E. Lewis, "FESH: X-Y Multi-Gp Neutron Transport PL Method (NRC Code)," ANL/NESC-861, 1985, Argonne NAtional Lab., IL

[98] C.P. Booker, Computer Implementation of Singular Function Enrichment of Finite-Element Methods for Multigroup Neutron Diffusion, PhD Dissertation, Texas A\&M University, College Station, TX, 1979

[99] M. Borisevich, "Finite Elements Method in Computation of the Neutron Distribution in Reactor Systems," Mtg. Spec. Meth. Comp. Programs for Phys. Calc. Fast Reactors, July 1, 1974, Dimitrovgrad, USSR, pp 195-200 (in Russian)

[100] J. Bouchard, A. Kavenoky and P. Reuss, "NEPTUNE: A Modular System for Light-Water Reactor Calculation," Trans. Am. Nucl. Soc., 20, 365-367 (1975)

[101] L. Bovio, V. Colombo, G.G.M. Coppa, G. Lapenta and P. Ravetto, "Two-Dimensional Transport with Highly Anisotropic Scattering," Ann. Nucl. Energy, 19, 639-653 (1992)

[102] L.L. Briggs, W.F. Miller Jr. and E.E. Lewis, "Ray-Effect Mitigation in Discrete Ordinate-Like Equations," Trans. Am. Nucl. Soc., 19, 165 (1974)

[103] L.L. Briggs, W.F. Miller Jr. and E.E. Lewis, "Ray-Effect Mitigation in Discrete Ordinate-Like Angular Finite Element Approximations in Neutron Transport," Nucl. Sci. Eng., 57, 205-217 (1975)

[104] L.L. Briggs and E.E. Lewis, "A Variational Coarse-Mesh Transport Method Based on Constrained Angular Trial Functions," Trans. Am. Nucl. Soc., 24, 183 (1976)

[105] L.L. Briggs and E.E. Lewis, "A Comparison of Constrained Finite Elements and Response Matrices as One-Dimensional Transport Approximations," Nucl. Sci. Eng., 63, 225-235 (1977)

[106] L.L. Briggs and E.E. Lewis, "Two-Dimensional Transport Applications of Constrained Finite Elements," Trans. Am. Nucl. Soc., 27, 350-351 (1977)

[107] L.L. Briggs, Constrained Finite Elements: A Coarse Mesh Technique for Solution of Neutron Transport Problems, PhD Dissertation, Northwestern Univ., Evanston, IL, 1978

[108] L.L. Briggs and E.E. Lewis, "A Two-Dimensional Constrained Finite Element Method for Nonuniform Lattice Problems," Nucl. Sci. Eng., 75, 76-87 (1980)

[109] C. Budd and E. Shuttleworth, "Extensions to the Finite-Element Code FENDER to Accomodate Three-Dimensional Problems," Proc. Int. Seminar on Finite Element and Allied Methods for Reactor Physics and Shielding Calculations, September 18-20, 1985, London, UK, published in Prog. Nucl. Energy, 18, 173-184 (1986) 
[110] P. Burda, "Finite Element Method Applied to the Eigenvalue Problem in Multigroup Diffusion Equations for Cylindrical Reactor," Acta Polytech. IV, 2, 5-24 (1975)

[111] C.R. Calabrese and C.R. Grant, "Use of Heterogeneous Finite Elements Generated by Collision Probability Solutions to Calculate a Pool Reactor Core," 18. Ann. Mtg. Argentine Assoc. Nucl. Technol. (AANT), October 22-26, 1990, Buenos Aires, Argentina, INIS-mf-13253 (in Spanish)

[112] C.R. Calabrese and C.R. Grant, "Use of Heterogeneous Finite Elements Generated by Collision Probability Solutions for a Reactor Core," Ann. Nucl. Energy, 20, 117-127 (1993)

[113] D.C. Carpenter and T.A. Parish, "Comparison of Finite Element and Global Element Methods in One-Dimensional Neutron Diffusion," Trans. Am. Nucl. Soc., 59, 156-157 (1989)

[114] D.C. Carpenter, A Comparison of the Finite 8 Global Element Methods in Neutron Diffusion Analysis, PhD Dissertation, Texas A\&M University, College Station, TX, 1989

[115] D.C. Carpenter and T.A. Parish, "Efficient Use of the Finite Element Method in Neutron Diffusion Analysis," Int. Conf. Physics of Reactors: Operation, Design and Computation, Physor 90, April 23-27, 1990, Marseille, France, Vol 3, pp PIV:116-PIV.125

[116] D.C. Carpenter, "Two-Dimensional Finite Element Neutron Diffusion Analysis Using Hierarchic Shape Functions," Proc. Joint Int. Conf. Mathematical Methods and Supercomputing for Nuclear Applications, October 5-9, 1997, Saratoga Springs, NY, Vol 1, pp 603-615, originally as WAPD-T-3133, March 1997, Bettis Atomic Power Laboratory

[117] C.L. Castrianni and M.L. Adams, "Asymptotic Diffusion Limit of Nonlinear Discontinuous Finite Element Transport Discretizations in One Dimension," Proc. Joint Int. Conf. Mathematical Methods and Supercomputing for Nuclear Applications, October 5-9, 1997, Saratoga Springs, NY, Vol 2, pp 1476-1486

[118] J. Cermak, V. Lelek, J. Schmid and V. Vesely, "Modern Mathematical Methods of Neutron Field Calculations in Real Reactor Geometry," Twenty Years of the Nuclear Research Institute, June 10, 1975, Rez, Czechoslovakia, pp 111-118 (in Czech)

[119] J. Cermak, J. Schmid and J. Weisner, "Finite Element Method for the Solution of Multidimensional Neutron Diffusion Equation," Acta Polytech. Rada IV. Tech.Teor., 3, 91-101 (1983)

[120] J. Cermak, V. Lelek and J. Vanicek, "Calculations of Criticality and Neutron Flux Density Distributions in LR-O Critical Assembly," Nukleon, 3 3-8 (1983) (in Czech) 
[121] Y. Chauvet, "Resolution of the Unsteady Transport Equation by Finite Element Methods," CEA-N-2079, January 1979, CEA Centre d'Etudes de Limeil, 94 Villeneuve-Saint-Georges, France (in French)

[122] K.Y. Cheung, Application of Finite-Element Method to Three-Dimensional Nuclear Reactor Analysis, PhD Dissertation, Polytechnic Inst. of New York, Brooklyn, NY, 1985

[123] E.P. Chivington, Considerations of the Effects of Azimuthal Fuel Motion in a Fast Breeder Reactor Accident, PhD Dissertation, Univ. California, Los Angeles, CA, 1980

[124] E.P. Chivington and W.E. Kastenberg, "On the Development of the Finite Element Method for Fast Reactor Kinetics with Material Motion," Nucl. Sci. Eng. 83, 350-365 (1983)

[125] S.J. Chucas, "The Treatment of Voided Regions in the Finite-Element Diffusion Code FENDER," Proc. Int. Seminar on Finite Element and Allied Methods for Reactor Physics and Shielding Calculations, September 18-20, 1985, London, England, published in Prog. Nucl. Energy, 18, 185-195 (1986)

[126] O.P. Chukhlova, "Reshenie Neodnorodnogo Sopryazhennogo Uravneniya Perenosa Nejtronov v Diffuzionnom Priblizhenii Metodom Galerkina v Dvumernoj Geometrii," NIIAR-P-26(292), 1976, Nauchno-Issledovatel'skij Inst. Atomnykh Reaktorov, Dimitrovgrad, USSR

[127] J.M. Collart, C. Fedon-Magnaud and J.J. Lautard, "Parallel Diffusion Calculation for the PHAETON On-Line Multiprocessor Computer," Int. Topl. Mtg. on Advances in Reactor Physics, Mathematics and Computation, April 27-30, 1987, Paris, France, Vol 1, pp 59-71

[128] V. Colombo, G. Coppa, P. Ravetto and M. Sumini, "Numerical Applications of the $A_{n}$ Transport Method for Stationary Reactor Physics Calculations," Proc. 1988 Int. Reactor Physics Conf., September 18-22, 1988, Jackson Hole, WY, Vol 2 , pp 135-144

[129] V. Colombo, G.G.M. Coppa, G. Lapenta and P. Ravetto, "New Angular Finite Element Techniques in Neutron Transport Calculations," Int. Conf. Physics of Reactors: Operation, Design and Computation, Physor 90, April 23-27, 1990, Marseille, France, Vol 3, pp PII.10-PII.19

[130] G.G.M. Coppa, G. Lapenta and P. Ravetto, "Angular Finite Element Techniques in Neutron Tranport," Ann. Nucl. Energy, 17, 363-378 (1990)

[131] G.G.M. Coppa, G. Lapenta and P. Ravetto, "Treatment of Scattering Anisotropy in Neutron Transport by Angular Finite Elements," Kerntechnik, 55, 377-381 (1990) 
[132] G.G.M. Coppa, P. Ravetto, G. Varda, L. Bovio, B. Montagnini and J.Y. Doriath, "Coarse Mesh-Boundary Element Scheme for Neutron Diffusion Problems in Hexagonal Geometry," Proc. Int. Conf. Reactor Physics and Reactor Computations, January 23-26, 1994, Tel Aviv, Israel, pp 633-640

[133] G.G.M. Coppa and P. Ravetto, "Quasi-Singular Finite Element Methods in Neutron Transport Problems," Transp. Theory Stat. Physics, 24, 155-172 (1995)

[134] A. Correia Filho, Solution of the Neutron Diffusion Equation at Two Groups of Energy by Method of Triangular Finite Elements, Thesis, Pernambuco Univ., Recife, Brazil, INIS-mf-7385, April 1981 (in Portuguese)

[135] A. Correia Filho, "Solution of Two Energy-Group Neutron Diffusion Equation by Triangular Elements," 2nd Nat. Mtg. Reactor Physics, April 13, 1981, Rio de Janeiro, Brazil (in Portuguese)

[136] F. Coulomb and C. Fedon-Magnaud, "Mixed and Mixed-Hybrid Elements for the Diffusion Equation," Int. Topl. Mtg. on Advances in Reactor Physics, Mathematics and Computation, April 27-30, 1987, Paris, France, Vol 1, pp 73-82

[137] F. Coulomb and C. Fedon-Magnaud, "Mixed and Mixed-Hybrid Elements for the Diffusion Equation," Nucl. Sci. Eng., 100, 218-225 (1988)

[138] F. Coulomb, "Domain Decomposition and Mixed Finite Elements for the Neutron Diffusion Equation," Proc. 2nd Int. Symp. Domain Decomposition Methods, January 14-16, 1988, Los Angeles, CA, pp 295-313

[139] F. Coulomb, "Domain Decomposition Method for Solving the Neutron Diffusion Equation," CEA-N-2599, March 1989, CEA Centre d'Etudes de Limeil, Villeneuve-Saint-Georges, France (in French)

[140] F. Coulomb, Parallel Algorithms for Solving the Diffusion Equation by Finite Element Methods and By Nodal Methods, DSci Thesis, CEA Centre d'Etudes Nucleaires de Saclay, France, 1989 (in French)

[141] F. Coulomb, "Domain Decomposition and Associate Block-Jacobi Method for the Diffusion Equation," 3rd Int. Symp. Domain Decomposition Meth. for Part. Diff. Eqns., 1989, Houston, TX, pp 410-427

[142] C.F. da Silva, "Synthesis Method with Finite Elements for Diffusion Calculations," 2nd Nat. Mtg. Reactor Physics, April 13, 1981, Rio de Janeiro, Brazil (in Portuguese)

[143] C.F. da Silva, "Synthesis Method with Finite Elements for Three-Dimensional Calculation," Ann. Prog. Report of 1981, INIS-BR-119, 1981, Inst. de Engenharia Nuclear, Rio de Janeiro, Brazil, pp 173-174 (in Portuguese)

[144] C.F. da Silva, "Synthesis Method with Finite Elements for Three-Dimensional Diffusion Multigroup Calculations," Ann. Prog. Report of 1982, INIS-BR-120, 1983, Inst. de Engenharia Nuclear, Rio de Janeiro, Brazil, pp 31-32 (in Portuguese) 
[145] J.W. Davidson, B.A. Clark, D.K. Marr, T.J. Seed, D.M. Davierwalla, C.E. Higgs and J. Stepanek, "TRISM: A Two-Dimensional, Discrete-Ordinates, Neutral Particle Transport Code with Deterministic Streaming Capabilities," Proc. Int.. Mtg. on Advances in Nucl. Eng. Computational Methods, April 9-11, 1985, Knoxville, TN, Vol 1, pp 167-170

[146] J.W. Davidson, D.J. Dudziak, S. Pelloni and J. Stepanek, "Two-Dimensional Cross-Section Sensitivity and Uncertainty Analysis of the LBM Experience at LOTUS," Fusion Technology 1988, Vol 2, The Netherlands, September 19-23, 1988, pp 1141-1147

[147] D.M. Davierwalla, "A Finite Element Solution to the Neutron Diffusion Equation in Two Dimensions," Int. Series in Numerical Math., 37, Birkhauser Verlag, 1977, pp $95-127$

[148] D.M. Davierwalla, "FINELM: A Multigroup Finite Element Diffusion Code. Part I. X-Y Geometry and Dissections," EIR-419, December 1980, Eidgenoessosches Inst. fuer Reaktorforschung, Wuerenlingen, Switzerland

[149] D.M. Davierwalla, S. Pelloni and D. Altiparmakov, "Finite Elements in Multidimensional Nuclear Diffusion," Proc. Int. Topl. Mtg. Advances in Math. Methods for the Soln. of Nucl. Eng. Problems, April 27-29, 1981, Munich, FRG, Vol 1, pp $335-348$

[150] D.M. Davierwalla, "FINELM : A Multigroup Finite Element Diffusion Code. Part I. R-Z Geometry and Numerical Accelerations," EIR-428, May 1981, Eidgenoessosches Inst. fuer Reaktorforschung, Wuerenlingen, Switzerland

[151] D.M. Davierwalla, C. Maeder and F. Schmidt, "Finite Elements and Nodal Methods in Diffusion Transport Theory and Advanced Reactor Calculations. Final Report of the Six-year Co-Ordinated Research Programme by the IAEA," IAEATECDOC-254, October 1981, pp 253-272

[152] D.M. Davierwalla, "FINELM (Computer Code Abstract)," Proc. Topl. Mtg. Advances in Reactor Computations, March 28-31, 1983, Salt Lake City, UT, Vol 1, pp 272-274

[153] D.M. Davierwalla, "The Mathematics of FINELM," Workshop Seminar on Finite Element Multidimensional Diffusion Codes, September 15-16, 1983, Saclay, France, published in Newsletter of the NEA Data Bank, No. 30, December 1983, pp 109-177

[154] D.M. Davierwalla, "FINELM: A Three Dimensional Finite Element Diffusion Code," Status Report: Common EPFL/PSI Project 'Numerical Simulation' For Year 1990, PSI-102, September 1991, Paul Scherrer Inst., Villigen, Switzerland, pp 31-36 
[155] C.R.E. de Oliveira, "An Arbitrary Geometry Finite Element Method for Multigroup Neutron Transport with Anisotropic Scattering," Proc. Int. Seminar on Finite Element and Allied Methods for Reactor Physics and Shielding Calculations, September 18-20, 1985, London, England, published in Prog. Nucl. Energy, 18, 227-236 (1986)

[156] C.R.E. de Oliveira, "Finite Element Model for Multigroup Neutron Transport with Anisotropic Scattering and Arbitrary Geometrie Domains," Proc. 6th Nat. Mtg. on Reactor Physics and Thermohydraulics, December 3, 1986, Sao Jose dos Campos, Brazil, pp 69-80

[157] C.R.E. de Oliveira, J. Wood and R.T. Ackroyd, "A Time-Dependent Finite Element Method for Radiation Transport," 3rd Int. Seminar on Finite Element and Allied Methods in Radiation Transport: Shielding, Reactor Physics, and Geophysics Applications, April 19-20, 1990, Imperial College, London, UK

[158] C.R.E. de Oliveira and A.J.H. Goddard, "Finite Element Transport Methods for Criticality Calculations - Current Status and Potential Applications," Proc. ICNC '91, Int. Conf. Nucl. Criticality Safety, September 9-13, 1991, Oxford, UK, Vol $3, \mathrm{p} 30$

[159] C.R.E. de Oliveira, R.T. Ackroyd and A.J.H. Goddard, "Finite Element Treatment of Nonlinear Thermal Radiation Transport," Trans. Am. Nucl. Soc., 68, 204-206 (1993)

[160] C.R.E. de Oliveira, C.C. Pain and A.J.H. Goddard, "Parallel Domain Decomposition Methods for Large-Scale Finite Element Transport Modelling," Proc. Int. Conf. Math. and Comp., Reactor Physics, and Env. Analyses, April 30-May 4, 1995, Portland, OR, Vol 1, pp 490-498

[161] C.R.E. de Oliveira, A.J.H. Goddard, C.C. Pain, and A.P. Umpleby, "ThreeDimensional Time-Dependent Finite Element Radiation Transport Methods for Criticality Assessment," Proc. 5th Intl. Conf. Nucl. Criticality Safety, Albu-. querque, NM, September 17-21, 1995, Vol 1, pp 6.38-6.43

[162] E. del Valle, L.M. Grossman, J.P. Hennart and D. Meade, "Some Aspects of Finite Element Dynamic Neutronic Analysis," Proc. Topl. Mtg. Advances in Reactor Computations, March 28-31, 1983, Salt Lake City, UT, Vol 1, pp 324-339

[163] E. del Valle-Gallegos, "Application of the Galerkin Finite Element Method to Reactor Dynamic Problems," Transp. Theory Stat. Phys., 12, 251-269 (1983)

[164] E. del Valle, J.P. Hennart and D. Meade, "Finite Element Formulations of Nodal Schemes for Neutron Diffusion and Transport Problems," Proc. Int. Mtg. on Advances in Nucl. Eng. Computational Methods, April 9-11, 1985, Knoxville, TN, Vol 2, pp 473-488 
[165] E. del Valle, J.P. Hennart and D. Meade, "Finite Element Formulations of Nodal Schemes for Neutron Diffusion and Transport Problems," Nucl. Sci. Eng., 92, 204-211 (1986)

[166] L.O. Deppe and K.F. Hansen, "Application of the Finite Element Method to TwoDimensional Diffusion Problems," Trans. Am. Nucl. Soc., 16, 132-133 (1973)

[167] L.O. Deppe and K.F. Hansen, "The Finite Element Method Applied to Neutron Diffusion Problems," COO-2262-1, February 1973, U.S. Atomic Energy Commission

[168] L.O. Deppe and K.F. Hansen, "Application of the Finite Element Method to Two-Dimensional Diffusion Problems," Nucl. Sci. Eng., 54, 456-465 (1974)

[169] J. Devooght, E.H. Mund and J.P. Hennart, "Extrapolated Implementation of Gordon's Projector with Application to Static Diffusion Calculations," Proc. Topl. Mtg. Advances in Reactor Computations, March 28-31, 1983, Salt Lake City, UT, Vol 1, pp 352-366

[170] M. Dhandhang P., M. Tsuji, M. Narita, and M. Itagaki, "A Hierarchical Domain Decomposition Boundary Element Method Applied to Neutron Diffusion Equation," Int. Conf. Physics of Reactors, PHYSOR 96 - Breakthrough of Nuclear Energy by Reactor Physics, September 16-20, 1996, Mito, Ibaraki, Japan, Vol 1, pp A.268-A.277

[171] M. Doering, "Application of the Finite Element Method (FEM) to Model Simulation and Control of Dynamic Processes in Large Nuclear Reactors," Wissenschaftliche Zeitschrift der Technischen Universitaet Dresden, 40, 101-103 (1991) (in German)

[172] J. Dorning, "Recent Developments in Multidimensional Reactor Physics Computational Capabilities," Trans. Am. Nucl. Soc., 49, 410-411 (1985)

[173] M.S. Du and C.F. Liu, "Stability and Convergence for the Discrete-Discontinuous Finite Element Method," J. Numer. Methods Comput. Appl., 5, 219-231 (1984) (in Chinese)

[174] M.S. Du and S.W. Fu, "A Two-Dimensional Discontinuous Finite Element Method for Solving the Transport Problem," J. Numer. Methods Comput. Appl., 7, 158168 (1986) (in Chinese)

[175] Y.V. Dubina and I.S. Slesarev, "Use of Finite Element Methods for Calculation of Nuclear Reactor Cylindrical Models in the Diffusional Approximation," Vestsi Akademii Navuk BSSR, Serya Fizika Energetychnykh Navuk, 4, 5-9 (1979) (in Russian)

[176] Y.V. Dubina and I.S. Slesarev, "Utilization of the Combined Method of Finite and Embedded Elements for Nuclear Reactor Analysis in the Diffusion Approximation," Vestsi Akad. Navuk BSSR, Ser. Fiz.-Energ. Navuk, 4, 122 (1980) (in Russian) 
[177] Y.V. Dubina, "Numerical Algorithm for the Solution of the Neutron Diffusion Problem Using the Finite Element Method with Regular Triangular Grids," Vestsi Akademii Navuk BSSR, Serya Fizika Energetychnykh Navuk, 3, 29-34 (1988) (in Russian)

[178] J.J. Duderstadt and W.R. Martin, Transport Theory, 1979, John Wiley \& Sons, New York, Sec. 8.3

[179] D.J. Dudziak and J. Stepanek, "Applicability of Finite Elements to Transport Theory (The Code TRIDENT)," Workshop Seminar on Finite Element Multidimensional Diffusion Codes, Saclay, France, September 15-16, 1983, published in Newsletter of the NEA Data Bank, No. 30, December 1983, pp 287-304

[180] T.L. Eaton and M.L. Adams, "New Corner-Balance / Linear-Discontinuous Method for Transport in Slab Geometry," Trans. Am. Nucl. Soc., 70, 158-159 (1994)

[181] P.G. Ellison, Coarse Mesh Finite Element Method for Boiling Water Reactor Physics Analysis, PhD Dissertation, Northwestern Univ., Evanston, IL, 1983

[182] P.G. Ellison and E.E. Lewis, "A Coarse Mesh Finite Element Method for Boiling Water Reactor Analysis," Proc. Topl. Mtg. Advances in Reactor Computations, March 28-31, 1983, Salt Lake City, UT, Vol 2, pp 1016-1029

[183] F.M. Eltawila, Optimum Idealization in Finite-Element Method for a Two-Group Neutron-Diffusion Problem, Thesis, Virginia Polytechnic Inst. and State Univ., Blacksburg, VA, 1974

[184] J.C. Estiot, D. Honde, G. Palmiotti and M. Salvatores, "Comparison of Finite Differences and Finite Elements in the Case of a Large Fast Power Reactor," Proc. Int. Seminar on Finite Element Methods in Radiation Physics, April 23-24, 1981, London Univ., London, UK, published in Ann. Nucl. Energy, 8, 609-620 (1981)

[185] A.M. Evans, D.D. Winstanley, N.H. Watmough and R. Gerber, "Application of FELTRAN to NEACRP TN12 Shipping Cask Benchmark," 3rd Int. Seminar on Finite Element and Allied Methods in Radiation Transport: Shielding, Reactor Physics, and Geophysics Appl., April 19-20, 1990, Imperial College, London, UK, published in Prog. Nucl. Energy, 25, 93-98 (1991)

[186] C. Fedon-Magnaud, J.P. Hennart and J.J. Lautard, "On the Relationship Between Some Nodal Schemes and the Finite Element Method in Static Diffusion Calculations," Proc. Topl. Mtg. Advances in Reactor Computations, March 28-31, 1983, Salt Lake City, UT, Vol 2, pp 987-1000

[187] C. Fedon-Magnaud, "Theoretical Study of Some Nodal Methods for the Solution of the Diffusion Equation. Numerical Tests," CEA-N-2358, August 1993, CEA Centre d'Etudes Nucleaires de Saclay, 91 - Gif-sur-Yvette, France (in French) 
[188] C. Fedon-Magnaud, J.J. Lautard, B. Akherraz and G.J. Wu, "Coarse Mesh Methods for the Transport Calculation in the CRONUS Reactor Code," Proc. Int. Conf. Math. and Comp., Reactor Physics, and Env. Analyses, April 30-May 4, 1995, Portland, OR, Vol 1, pp 508-526

[189] C. Fedon-Magnaud and K. Pinchedez, "Parallel Transport Calculations with the CRONOS Reactor Code," Proc. Joint Int. Conf. Mathematical Methods and Supercomputing for Nuclear Applications, October 5-9, 1997, Saratoga Springs, NY, Vol 1, pp 394-403

[190] M. Feng, "Streamline Diffusion Finite Element Methods for Nonlinear Neutron Transport Equations," J. Xi'an Jiaotong Univ., 26, 123-126 (1992)

[191] D.R. Ferguson, "Multidimensional Reactor Dynamics Today: An Overview," Proc. Conf. Computational Methods in Nuclear Engineering, April 15-17, 1975, Charleston, SC, Vol 2, pp VI.49-VI.67

[192] J.M. Ferguson, "A Modified Finite Elements Method for the Neutron Transport Equation," Trans. Am. Nucl. Soc., 33, 328-329 (1979)

[193] J.M. Ferguson and A. Greenbaum, "A Finite Element Method for Solving Neutron Transport Problems," ANS Topl. Mtg. Reactor Physics and Shielding, September 17-19, 1984, Chicago, IL, also found as UCRL-90579, March 1984, Lawrence Livermore Laboratory

[194] A. Fernandes and J.R. Maiorino, "Solutions of Transport Equation in (X-Y-Z) Three-Dimensional Geometry by Finite Element Method and Spherical Harmonic Expansion," Proc. 7th Nat. Mtg. Reactor Physics and Therm. Hydr., April 26-28, 1989, Recife, Brazil, Vol 1, pp 73-84 (in Portuguese)

[195] A. Fernandes and J.R. Maiorino, "The Solution of the One Speed, Three Dimensional Neutron Transport Equation Using the Finite Element Method and the Associated Legendre Function," 3rd Int. Seminar on Finite Element and Allied Methods in Radiation Transport: Shielding, Reactor Physics, and Geophysics Applications, April 19-20, 1990, Imperial College, London, UK

[196] A. Fernandes and J.R. Maiorino, "EDEF: A Program for Solving the Neutron Diffusion Equation Using Microcomputers," 3. General Brazilian Congress of Nuclear Energy, July 22-27, 1990, Rio de Janeiro, Brazil (in Portuguese)

[197] A. Fernandes, "Study of a Method to Solve the One Speed, Three Dimensional Transport Equation Using the Finite Element Method and the Associated Legendre Function," INIS-BR-2982, 1991, Inst. de Pesquisas Energeticas e Nucleares, Sao Paulo, Brazil (in Portuguese)

[198] A. Fernandes and J.R. Maiorino, "Solution of the Three Space Dimensions and One Group Transport Equation Using Finite Element Method and Spherical Harmonics Expansion," Proc. 9th Brazilian Mtg. Reactor Physics and Therm. Hydr., October 25-28, 1993, Caxambu, Brazil, pp 48-53 (in Portuguese) 
[199] W.L. Filippone, "The Finite Element Formulation of the Streaming Ray Method," Transp. Theory Stat. Phys., 12, 323-337 (1983)

[200] W.L. Filippone, J.P. Hennart and E. Real, "Cross-Directional Coarse- and FineMesh Trial Functions," Trans. Am. Nucl. Soc., 33, 330-332 (1979)

[201] G.J. Fix, S. Gulati and G.I. Wakoff, "On the Use of Singular Functions with Finite Element Approximations," J. Comput. Phys., 13, 209-228 (1973)

[202] J.K. Fletcher, "Finite Element Option for the MARC Transport/Diffusion Theory Computer Code," ND-R-560(R), December 1980, UKAEA Risley Nuclear Power Development Establishment, UK

[203] J.K. Fletcher, "A Solution of the Multigroup Transport Equation Using a Weighted Residual Technique," Proc. Int. Seminar on Finite Element Methods in Radiation Physics, April 23-24, 1981, London Univ., London, UK, published in Ann. Nucl. Energy, 8, 647-656 (1981)

[204] J.K. Fletcher, "A Solution of the Neutron Transport Equation Using Spherical Harmonics," J. Physics A (Mathematical and General), 16, 2827-2835 (1983)

[205] J.K. Fletcher, "The Solution of the Multigroup Neutron Transport Equation Using Spherical Harmonics," Nucl. Sci. Eng., 84, 33-46 (1983)

[206] J.K. Fletcher, "Finite Element Solution of the Three-Dimensional Neutron Transport Equation," The Mathematics of Finite Elements and Applications - MAFELAP V, J.R. Whiteman (ed.), Academic Press, London, (1985), pp 611-612

[207] J.K. Fletcher, "Recent Developments of the Transport Theory Code MARC/PN," Prog. Nucl. Energy, 18, 75-83 (1986)

[208] J.K. Fletcher, "Recent Developments of the MARC/PN Transport Theory Code," Int. Topl. Mtg. on Advances in Reactor Physics, Mathematics and Computation, April 27-30, 1987, Paris, France, Vol 3, pp 1319-1332

[209] J.K. Fletcher, "Recent Developments of the MARC/PN Transport Theory Code Including a Treatment of Anisotropic Scatter," RTS-R-001, December 1987, UKAEA Risley Technical Services, Risley, UK

[210] J.K. Fletcher, "A Solution of the Multigroup Transport Equation in Curvilinear Co-Ordinates," Int. Conf. on the Physics of Reactors: Operation, Design and Computation, April 23-27, 1990, Marseille, France, Vol 3, pp II.20-II.27

[211] J.K. Fletcher, "MARC/PN: A Computer Program to Solve the Multigroup Neutron Transport Equation," RTS-R-002, July 1988, UKAEA Risley Technical Services, Risley, UK

[212] H.P. Franke and F.A.R. Schmidt, "FEM2D ein Programm zur Losung der Zweidimensionalen Diffusionsg; Eichung nach der Methode der Finiten Elemente," IKE-4-25, 1974, English Translation in ORNL-TR-2971 
[213] H.P. Franke, E. Sapper and F.A.R. Schmidt, "Two- and Three-Dimensional Reactor Physics Calculations with the Finite Element Method," Atomkernenergie, 26, 158-162 (1975)

[214] H.P. Franke, "Untersuchungen zur Numerischen Losung Dreidimensionaler Stationarer Diffusionssgleichugen nach der Methode der Finiten Elemente, Dissertationsschrift," IKE-4-53, 1976 (in German)

[215] H.P. Franke, "Anwendung der Methode der Finiten Elemente bei der Berechnung Dreidimensionaler Reaktorphysikalischer Probleme," Atomkerenergie, 30, 88-94 (1977) (in German)

[216] H.P. Franke, "Using the Finite Element Method to Calculate Three-Dimensional Problems in Reactor Physics," Tech. Mtg. Coarse-Mesh Methods: Progress in the Methods and Their Appl. Reactor Prob., Abstracts, January 25, 1977, Erlangen, FRG (in German)

[217] R. Fremd, "Solution of the Reactor Kinetics Equation in Two and Three Dimensions by Means of the Finite Element Method," IKE-4-100, January 1981, Inst. fuer Kernenergetik und Energiesysteme

[218] R. Froehlich, "Current Problems in Multidimensional Reactor Calculations," Proc. Mathematical Models and Computational Techniques for Analysis of Nuclear Systems, April 9-11, 1973, Ann Arbor, MI, Vol 2, pp VII.1-VII.66

[219] T. Fujimura, T. Tsutsui, K. Horikami, Y. Nakahara and T. Ohnishi, "Application of Finite Element Method to Two-Dimensional Multi-Group Neutron Transport Equation in Cylindrical Geometry," J. Nucl. Sci. Technol., 14, 541-550 (1977)

[220] T. Fujimura, T. Tsutsui, K. Horikami, Y. Nakahara and T. Ohnishi, "FEMRZ: Program for Solving Two-Dimensional Neutron Transport Problems in Cylindrical Geometry by the Finite Element Method," JAERI-1253, February 1978, Japan Atomic Energy Research Inst., Tokyo

[221] T. Fujimura, Y. Nakahara and M. Matsumura, "Application of Space- and Angle Finite Element Method to the Three Dimensional Neutron Transport Problems," Proc. 6th Int. Conf. on Radiation Shielding 1, May 16, 1983, Tokyo, Japan, pp $302-311$

[222] T. Fujimura, Y. Nakahara and M. Matsumura, "Solution of Three-Dimensional Neutron Transport Equation by Double Finite Element Method," J. Nucl. Sci. Technol., 20, 620-623 (1983)

[223] T. Fujimura, Y. Nakahara and M. Matsumura, "Algorithm for Solving ThreeDimensional Neutron Transport Problems by the Galerkin-Type Double Finite Element Method," JAERI-M-83-144, September 1983, Japan Atomic Energy Research Inst., Tokyo (in Japanese) 
[224] T. Fujimura, "Double Finite-Element Method with Accurate Reflective Boundary Condition Treatment for Three-Dimensional Transport," Comp. Physics Comm., 82, 111-119 (1994)

[225] T. Fujimura, et al., "Development of Three-Dimensional Transport Code by the Double Finite Element Method," Proc. Seminar on Software Development in Nuclear Energy Research, September 27, 1984, Tokai, Ibaraki, Japan, pp 120-131 (in Japanese)

[226] J. Gado, "Solution of 2D and 3D Hexagonal Geometry Benchmark Problems by Using the Finite Element Diffusion Code DIFGEN," IKE-4-121, February 1986, Inst. fuer Kernenergetik und Energiesysteme, FRG

[227] J. Gado, "A New Trial Function for Hexagons," Ann. Nucl. Energy, 13, 685-688 (1986)

[228] J. Gado and F. Schmidt, "Comparison of Various Approaches to the Solution of the Neutron Diffusion Equation in Hexagonal Geometries," Int. Topl. Mtg. on Advances in Reactor Physics, Mathematics and Computation, April 27-30, 1987, Paris, France, Vol 3, pp 1197-1202

[229] J. Galliara and M.M.R. Williams, "A Finite Element Method for Neutron Transport - II. Some Practical Considerations," Ann. Nucl. Energy, 6, 205-223 (1979)

[230] B.A. Ganapol, J.A. Roybal and A.K. Henninger, "Time-Dependent Neutron Transport in Spherical Geometry," Trans. Am. Nucl. Soc., 32, 312-314 (1979)

[231] E.M. Gelbard, "Status of the Finite Element Method in Diffusion Calculations," FRA-TM-55, 1973, Argonne Nat. Lab, IL

[232] E.M. Gelbard, "Monte Carlo, Finite Element and $S_{N}$ Methods," Proc. Conf. Computational Methods in Nuclear Engineering, April 15-17, 1975, Charleston, SC, Vol 2, pp III.1-III.14

[233] J. Gerin-Roze and P. Lesaint, "Isoparametric Finite Element Methods for TwoDimensional Transport Calculations," Int. J. Numer. Methods Eng., 10, 171-183 (1976)

[234] J. Gerin-Roze, "Sur L'Application de la Methode des Elements Finis a la Resolution de L'Equation de Boltzmann Stationnaire," CEA-R-4916, August 1978, CEA Centre d'Etudes de Limeil, 94 - Villeneuve-Saint-Georges, France (in French)

[235] J. Gerin-Roze, Application of the Finite Element Method to Solution of the Static Boltzmann Equation, Paris Universite, Paris, France, 1978 (in French)

[236] T.A. Germogenova and A.I. Ilyushkin, "Application of the Variational Method for Solution of a Transport Equation in the Plane with Azimuthal Symmetry and Spherical Geometries," Approx. and Interpolation Methods, 1980, Novosibirsk, pp 49-61 (in Russian) 
[237] S.A.W. Gerstl and A. Zardecki, "Discrete-Ordinates Finite-Element Method for Atmospheric Radiative Transfer and Remote Sensing," Applied Optics, 24, 81-93 (1985)

[238] A. Greenbaum and J.M. Ferguson, "A Petrov-Galerkin Finite Element Method for Solving the Neutron Transport Equation," J. Comput. Phys., 64, 97-111 (1986)

[239] D.T. Grenfell, "The Application of the Finite Element Method to the Solution of Radiation-Shielding Problems," Proc. Int. Seminar on Finite Element Methods in Radiation Physics, April 23-24, 1981, London Univ., London, UK, published in Ann. Nucl. Energy, 8, 581-596 (1981)

[240] D.T. Grenfell, "The Solution of the Two-Dimensional Steady State Transport Equation by a Reduction to a Set of Coupled Diffusion Order Equations," Workshop Seminar on Finite Element Multidimensional Diffusion Codes, Saclay, France, September 15-16, 1983, published in Newsletter of the NEA Data Bank, No. 30, December 1983, pp 52-108

[241] L.M. Grossman, J.P. Hennart and D. Meade, "Finite Element Collocation Methods for Space-Time Reactor Dynamics," Trans. Am. Nucl. Soc., 41, 311-312 (1982)

[242] L. Gu, Y. Wang, S. Yu and W. Zong, "Application of the Finite Element Method to Two-Dimensional Neutron Diffusion Equation in Reactor Physics," J. Qing Hua Univ., 20, 97-110 (1980) (in Chinese)

[243] B.L. Guo and L. J. Shen, "The Galerkin Finite Element Solution for the Nonlinear Neutron Transport Equation," Comm. Appl. Math. Comput., 3, 8-20 (1989) (in Chinese)

[244] J. Hadek, "Space-Time Reactor Kinetics Code ADKIN," Nucleon, 3, 8-13 (1991)

[245] L.A. Hageman, "The Solution of Linear Equations Resulting from Finite Element Discretizations of Multi-Dimensional Boundary Value Problems," WAPD-TM1209, August 1975, Bettis Atomic Power Laboratory

[246] K.F. Hansen and C.M. Kang, "Finite Element Methods in Reactor Physics Analysis," Adv. Nucl. Sci. Technol., 8, 173-253 (1975)

[247] K.F. Hansen and C.M. Kang, "Progress Report No. 32, 9 September $1975-12$ December 1975," C00-2262-32, Mass. Inst. Tech., Cambridge, Mass

[248] K.F. Hansen and A.F. Henry, "Annual Progress Report FY 1977 (Computer Calculations of Light Water Reactor Dynamics and Safety)," C00-2262-13, July 1977, Mass. Inst. Tech., Cambridge, Mass

[249] D.D. Hardin, Singular Function Enriched Finite Element Methods for Multigroup Neutron Diffusion Problems, PhD Dissertation, Texas A\&M Univ., College Station, TX, 1977 
[250] D.D. Hardin, P.W. Smith and R.S. Wick, "Singularities in Diffusion Theory Eigenvalue Problems," Proc. Topl. Mtg. Comput. Meth. in Nucl. Eng., April 23-25, 1979, Williamsburg, VA, Vol 1, pp 3.105-3.117

[251] M.Z. Hasan, Application of Diffusion Theory to the Transport of Neutral Particles in Fusion Plasmas, PhD Dissertation, Univ. California, Los Angeles, 1985

[252] M.Z. Hasan and R.W. Conn, "A Two-Dimensional Finite Element Multigroup Diffusion Theory for Neutral Atom Transport in Plasmas," J. Comput. Phys., 71, 371-390 (1987)

[253] M. Havranek, "Internal Material Limitations in the Loops of Finite-Difference Methods," Jahrestagung Kerntechnik '81 (Nuclear Technology 1981), March 2426 1981, Dusseldorf, W. Germany, pp 51-54 (in German)

[254] M. Hayashi, S. Shiroya, K. Kanda and T. Shibata, "Calculation of the MEU-HEU Coupled Core in the KUCA," Proc. Int. Mtg. on Reduced Enrichment for Research and Test Reactors, October 24, 1983, Tokai, Japan, as found in JAERI-M-84-073, May 1984, pp 377-387

[255] A. Hebert, "Application of the Hermite Method for Finite Element Reactor Calculations," Nucl. Sci. Eng., 91, 34-58 (1985)

[256] A. Hebert, "Variational Principles and Convergence Acceleration Strategies for the Neutron Diffusion Equation," Nucl. Sci. Eng., 91, 414-427 (1985)

[257] A. Hebert, "Application of a Dual Variational Formulation to Finite Element Reactor Calculations," Ann. Nucl. Energy, 20, 823-845 (1993)

[258] J.P. Hennart, "Piecewise Polynomial Approximations with Extrapolation for Multidimensional Diffusion Equations," Trans. Am. Nucl. Soc., 15, 297 (1972)

[259] J.P. Hennart, A. Jaucot and V. Renda, "Piecewise Polynomial Approximations for the One and Two Dimensional Space Time Kinetics Equations," Proc. Seminar on Numerical Reactor Calculations, January 17-21, 1972, Vienna, Austria, Int. Atomic Energy Agency, pp 675-688

[260] J.P. Hennart, "Comparison of Extrapolation Techniques with High Order Finite Element Methods for Diffusion Equations with Piecewise Continuous Material Properties," Proc. Mathematical Models and Computational Techniques for Analysis of Nuclear Systems, April 9-11, 1973, Ann Arbor, Mich, pp VII.95-VII.119

[261] J.P. Hennart and E.H. Mund, "Singularities in the Finite Element Approximation of Two-Dimensional Diffusion Problems," Trans. Am. Nucl. Soc., 17, 239-240 (1973)

[262] J.P. Hennart, "Comments on 'Finite-Element Methods for Reactor Analysis'," Nucl. Sci. Eng., 56, 225-226 (1975) 
[263] J.P. Hennart, J.G. Martin and J. Sanchez Gutierrez, "A Finite Element Plasma Diffusion Code for Arbitrary Toroidal Geometry," Trans. Am. Nucl. Soc., 21, 225-226 (1975)

[264] J.P. Hennart and E.H. Mund, "Singularities in the Finite Element Approximation of Two-Dimensional Diffusion Problems," Nucl. Sci. Eng., 62, 55-68 (1977)

[265] J.P. Hennart, J.G. Martin and J. Sanchez G., "A Finite Element Code for the Time-Dependent Plasma Diffusion in Arbitrary Toroidal Geometry," Nucl. Sci. Eng., 64, 768-778 (1977)

[266] J.P. Hennart, "Piecewise Polynomials for Point and Space Kinetics with Variable Reactivity," Trans. Am. Nucl. Soc., 19, 179-180 (1974)

[267] J.P. Hennart, "Piecewise Polynomial Approximations for Nuclear Reactor Point and Space Kinetics," Nucl. Sci. Eng., 64, 875-882 (1977)

[268] J.P. Hennart, "Finite Elements in Time and Space for Transient Reactor Neutronics Analysis," Proc. Topl. Mtg. Computational Methods in Nucl. Eng., April 23-25, 1979, Williamsburg, VA, Vol 1, pp 3.119-3.133

[269] J.P. Hennart, E. Sainz M. and M. Villegas G., "On the Efficient Use of the Finite Element Method in Static Neutron Diffusion Calculations," Proc. Topl. Mtg. Computational Methods in Nucl. Eng., April 23-25, 1979, Williamsburg, VA, Vol $1, \mathrm{pp} 3.87-3.103$

[270] J.P. Hennart, "A Unified Formalism for Spatial Discretization Schemes of Transport Equations in Slab Geometry," Proc. Int. Seminar on Finite Element Methods in Radiation Physics, April 23-24, 1981, London Univ., London, UK, published in Ann. Nucl. Energy, 8, 677-681 (1981)

[271] J.P. Hennart, "A Unified View of Finite Differences, Finite Elements, and Nodal Schemes," Int. Topl. Mtg. on Advances in Reactor Physics, Mathematics and Computation, April 27-30, 1987, Paris, France, Vol 3, pp 1289-1294

[272] J.P. Hennart, E. Del Valle and C. Filio, "New Nodal Finite Element Methods for the Numerical Solution of the Discrete-Ordinates Equations in X-Y Geometry," Int. Topl. Mtg. Advances in Mathematics, Computations, and Reactor Physics, April 28-May 2, 1991, Pittsburgh, PA, Vol 2, pp 7.1 1-1 - 7.1 1-11

[273] J.P. Hennart, "A Finite Element Approach to Point- and Mesh-Centered Finite Difference Schemes over Rectangular Grids," Ann. Nuclear Energy, 19, 663-678 (1992)

[274] J.P. Hennart, E. Malambu, E.H. Mund and E. del Valle, "A Comparison of Various Nodal Finite Element Formulations for Neutron Multigroup Diffusion Equations," Proc. Int. Conf. Math. and Comp., Reactor Physics, and Env. Analyses, April 30May 4, 1995, Portland, OR, Vol 2, pp 1388-1399 
[275] J.P. Hennart, E.H. Mund and E. del Valle, "Transverse Integration on Composite Nodal Finite Elements for Hexagons," Proc. Joint Int. Conf. Mathematical Methods and Supercomputing for Nuclear Applications, October 5-9, 1997, Saratoga Springs, NY, Vol 1, pp 93-102

[276] J.P. Hennart, E.H. Mund and E. del Valle, "A Composite Nodal Finite Element for Hexagons," Nucl. Sci. Eng., 127, 139-153 (1997)

[277] J.P. Hennart and E. del Valle, "New Nodal Finite Element Schemes for the Discrete Ordinates Transport Equation," Proc. Joint Int. Conf. Mathematical Methods and Supercomputing for Nuclear Applications, October 5-9, 1997, Saratoga Springs, NY, Vol 1, pp 19-28

[278] A. Henry, Nuclear-Reactor Analysis, 1975, Mass. Inst. Tech., Sect. 11.5

[279] C.E. Higgs and D.M. Davierwalla, "FINELM: A Multigroup Finite-Element Diffusion Code. Input Description, Program Description and Test Examples," EIR-442, June 1981, Eidgenoessisches Inst. fuer Reaktorforschung, Wuerenlingen, Switzerland

[280] C.E. Higgs, "FINELM Architecture and Usage," Workshop Seminar on Finite Element Multidimensional Diffusion Codes, Saclay, France, September 15-16, 1983, published in Newsletter of the NEA Data Bank, No. 30, December 1983, pp 178259

[281] T.R. Hill, "ONETRAN: A Discrete Ordinates Finite Element Code for the Solution of the One-Dimensional Multigroup Transport Equation," LA-5990-MS, 1975, Los Alamos, New Mexico

[282] T.R. Hill, "The Linear Discontinuous Finite Element Scheme in Time-Dependent Transport Calculations," Trans. Am. Nucl. Soc., 21, 228-230 (1975)

[283] T.R. Hill and W.H. Reed, "TIMEX: A Time-Dependent Explicit Discrete Ordinates Program for the Solution of Multigroup Transport Equations With Delayed Neutrons," LA-6201-MS, January 1976, Los Alamos Scientific Lab., New Mexico

[284] J.P. Holloway and G. Wojtowicz, "Spectral and Finite Element Techniques Employing an Alternative Lattice Representation," Trans. Am. Nucl. Soc., 71, 242244 (1994)

[285] W. Hongchun and X. Zhongsheng, "The Finite Element Approximation of TwoDimensional Neutron Diffusion Equations of Fast Reactor," Nucl. Power Eng., 13, 26-31 (1992) (in Chinese)

[286] K. Horikami, Y. Nakahara, T. Fujimura and T. Ohnishi, "Finite Element Method for Solving Neutron Transport Problems in Two-Dimensional Cylindrical Geometry," JAERI-M-5793, July 1974, Japan Atomic Energy Research Inst., Tokai, Ibaraki, Japan 
[287] A.X. Huang, Q.H. Huang, Y.R. Tang and Z.G. Tu, "The Finite Element Approximation of the Eigenvalue Problem of Three-Dimensional Multigroup Neutron Diffusion Equations and Accelerating Convergence Method," Proc. China-France Symp. on Finite Element Methods, April 19-23, 1982, Beijing, China, pp 659-695

[288] A.X. Huang, Q.H. Huang, Y.R. Tang and Z.G. Tu, "The Finite Element Solution of the Eigenvalue Problem of the Three-Dimensional Neutron Diffusion Equations, and a Method For Accelerating Its Convergence," J. Xi'an Jiaotong Univ., 17, 15-26 (1983) (in Chinese)

[289] M.A. Ibrahim, "Theoretical Prediction of Neutron Propagation in Pure Sodium," Nucl. Sci. J., 27, 483-486 (1990)

[290] M. Imasaki and M. Ooki, "Stability Analysis of Linearized Nuclear Reactor by Finite Element Method," J. Nucl. Sci. Tech., 14, 551-557 (1977)

[291] N.V. Isaev, I.S. Slesarev, N.E. Gorbatov and A.P. Ivanov, "Two-Dimensional Kinetic Calculation of Nuclear Reactor by the Finite-Elements Method," Atomic Energy (USSR), 41, 391-395 (1976) (in Russian). English Translation in Soviet At. Energy, 41, 1042-1046 (1976)

[292] T. Ise, Y. Nakahara and T. Yamazaki, "FEM-BABEL: A Computer Program for Solving Three-Dimensional Neutron Diffusion Equation by the Finite Element Method," JAERI-1256, March 1978, Japan Atomic Energy Research Inst., Tokyo

[293] T. Ise, "FEM-BABEL," Workshop NEA Data Bank Software, May 5, 1980, Argonne, IL, published in Newsletter of NEA Data Bank, No 26., 167-192 (1981)

[294] M. Ishiguro and K. Higuchi, "Application of Hexagonal Element Scheme in Finite Element Method to Three-Dimensional Diffusion Problem of Fast Reactors," JAERI-M-82-071, July 1982, Japan Atomic Energy Research Inst., Tokyo

[295] M. Ishiguro and K. Higuchi, "Application of Hexagonal Element Scheme in Finite Element Method to Three-Dimensional Diffusion Problem of Fast Reactors," J. Nucl. Sci. Technol., 20, 951-960 (1983)

[296] M. Ishiguro, et al., "Experience with the Vectorization of Nuclear Codes," Proc. Seminar on Software Development in Nuclear Energy Research, September 27, 1984, Tokai, Ibaraki, Japan, pp 151-170 (in Japanese)

[297] J.G. Issa, N.S. Riyait, A.J.H. Goddard and G.E. Stott, "Multigroup Application of the Anisotropic FEM Code FELTRAN to One, Two, Three-Dimensions and R-Z Problems," Proc. Int. Seminar on Finite Element and Allied Methods for Reactor Physics and Shielding Calculations, September 18-20, 1985, London, England, published in Prog. Nucl. Energy, 18, 251-264 (1986)

[298] M. Itagaki, "Boundary Element Methods Applied to Two-Dimensional Neutron Diffusion Problems," J. Nucl. Sci. Tech., 22, 565-583 (1985) 
[299] M. Itagaki, "Boundary Element Techniques for Two-Dimensional Nuclear Reactor Calculations," Eng. Analysis, 4, 190-198 (1987)

[300] M. Itagaki and C.A. Brebbia, "Boundary Element Method Applied to Neutron Diffusion Problems," 10th Int. Conf. Boundary Element Methods, September 1988, Southampton, England, Vol 2, pp 45-56

[301] M. Itagaki and C.A. Brebbia, "Space-Dependent Core/Reflector Boundary Conditions Generated by the Boundary Element Method for Pressurized Water Reactors," Nucl. Sci. Eng., 107, 246-264 (1991)

[302] M. Itagaki and C.A. Brebbia, "Boundary Element Formulation of Fission Neutron Source Problems Using Only Boundary Integrals," Eng. Anal. with Boundary Elements, 8, 239-244 (1991)

[303] M. Itagaki and C.A. Brebbia, "Remedy for Round-off Error Accumulation Observed in a Neutron Diffusion Calculation Using the Multiple Reciprocity Boundary Element Method," Eng. Anal. with Boundary Elements, 10, 345-352 (1992)

[304] M. Itagaki, Y. Miyoshi and H. Hirose, "Geometric Buckling Expression for Regular Polygons: II. Analyses Based on the Multiple Reciprocity Boundary Element Method," Nucl. Technol., 103, 392-402 (1993)

[305] M. Itagaki and C.A. Brebbia, "Generation of Higher Order Fundamental Solutions to the Two-Dimensional Modified Helmholtz Equation," Eng. Anal. with Boundary Elements, 11, 87-90 (1993)

[306] M. Itagaki and C.A. Brebbia, "Multiple Reciprocity Boundary Element Formulation for One-Group Fission Neutron Source Iteration Problems," Eng. Anal. with Boundary Elements, 11, 39-45 (1993)

[307] M. Itagaki, "Boundary Element Method for Criticality Safety Analyses," Proc. 5th Intl. Conf. Nucl. Criticality Safety, Albuquerque, NM, September 17-21, 1995, Vol 1 , pp $6.25-6.31$

[308] M. Itagaki and N. Sahashi, "Three-Dimensional Isoparametric Boundary Element Method for Solving Neutron Diffusion Equations," J. Nucl. Sci. Tech., 33, 7-16 (1996)

[309] M. Itagaki and N. Sahashi, "Three-Dimensional Multiple Reciprocity Boundary Element Method for One-Group Neutron Diffusion Eigenvalue Computations," $J$. Nucl. Sci. Tech., 33, 101-109 (1996)

[310] M. Itagaki and N. Sahashi, "Matrix-Type Multiple Reciprocity Boundary Element Method for Solving Three-Dimensional Two-Group Neutron Diffusion Equations," J. Nucl. Sci. Tech., 34, 655-665 (1997)

[311] A. Jaber, Various Types of Numerical Schema for the One-Dimensional Spherical Geometry Transport Equation, DSc Thesis, FRNC-TH-1114, July 1981, Besancon Univ., France (in French) 
[312] J.C. Jacquin and K.F. Hansen, "Finite Element Solutions for Multiregion Problems," Trans. Am. Nucl. Soc., 17, 238-239 (1971)

[313] V. Jagannathan and C.P. Cali, "Single Channel Sysnthesis with Finite Element Trial Functions for Three-Dimensional Reactor Calculations," Atomkernenerg./Kerntech., 35, 25-29 (1980)

[314] V. Jagannathan and B.P. Rastogi, "An Assessment of Finite Element Synthesis Model Using 3D FEM," Int. Conf. on Numerical Methods in Nucl. Eng., September 6-9, 1983, Montreal, Canada, Vol 1, pp 249-268

[315] V. Jagannathan, "Evaluation of the Finite-Element-Synthesis Model Using the 3-D Finite-Element Technique," Ann. Nucl. Energy, 10, 569-578 (1983)

[316] V. Jagannathan, "FEMSYN - A Code System to Solve Multigroup Diffusion Theory Equations Using a Variety of Solution Techniques. Part 3: FINERC - The Finite Element Module," BARC-1267, 1985, Bhabda Atomic Research Centre, Bombay, India

[317] V. Jagannathan, "FEMSYN - A Code System to Solve Multigroup Diffusion Theory Equations Using a Variety of Solution Techniques. Part 4: SYNTHD - The Synthesis Module," BARC-1268, 1985, Bhabda Atomic Research Centre, Bombay, India

[318] V. Jagannathan, "Application of the Finite-Element-Synthesis Model to Multidimensional Reactor Transient Problems Without Feedback," Ann. Nucl. Energy, 12, 583-591 (1985)

[319] V. Jagannathan, "An Analysis of Multidimensional Reactor Transients Using Reduced Integration Techniques in the Finite Element Method," Ann. Nucl. Energy, 13, 379-390 (1986)

[320] C. Johnson and J. Pitkaranta, "Convergence of a Fully Discrete Scheme for TwoDimensional Neutron Transport," SIAM J. Numer. Anal., 20, 951-966 (1983)

[321] C.M. Kang and K.F. Hansen, "Finite Element Methods for the Neutron Diffusion Equations," Trans. Am. Nucl. Soc., 14, 199-200 (1971)

[322] C.M. Kang, "Piecewise Polynomial Approximations for the Point Kinetics Equations," Trans. Am. Nucl. Soc., 14, 201-202 (1971)

[323] C.M. Kang and K.F. Hansen, "Finite Element Methods for Space-Time Reactor Analysis," MIT-3903-5, 1971, U.S. Atomic Energy Comm.

[324] C.M. Kang and K.F. Hansem, "Finite Element Methods for Space-Time Reactor Analysis," MIT-NE135, 1971, Mass. Inst. Tech., Cambridge, Mass.

[325] C.M. Kang and K.F. Hansen, "Finite Element Methods for Reactor Analysis," Nucl. Sci. Eng., 51, 456-495 (1973) 
[326] C.M. Kang and K.F. Hansen, "Response to "Comments on 'Finite Methods for Reactor Analysis'"," Nucl. Sci. Eng., 56, 226-228 (1975)

[327] H.G. Kaper, G.K. Leaf and A.J. Lindeman, "Application of Finite Element Techniques for the Numerical Solution of the Neutron Transport and Diffusion Equations," Second Conf. on Transport Theory, January 26-29, 1971, Los Alamos Nat. Lab., Los Alamos, NM, CONF-710107, April 1971, pp 258-285

[328] H.G. Kaper, G.K. Leaf and A.J. Lindeman, "The Use of Interpolatory Polynomials for a Finite Element Solution of the Multigroup Diffusion Equation," Trans. Am. Nucl. Soc., 15, 298-299 (1972)

[329] H.G. Kaper, G.K. Leaf and A.J. Lindeman, "A Timing Comparison Study for Some High Order Finite Element Approximation Procedures and a Low Order Finite Difference Approximation Procedure for the Numerical Solution of the Multigroup Neutron Diffusion Equation," Nucl. Sci. Eng., 49, 27-48 (1972)

[330] H.G. Kaper, G.K. Leaf and A.J. Lindeman, "Applications of Finite Element Methods in Reactor Mathematics. Numerical Solution of the Neutron Diffusion Equation," ANL-7925, 1972, Argonne Nat. Lab., IL

[331] H. Kaper, G. Leaf and A. Lindeman, "An Approximation Procedure for the Neutron Transport Equation Based on the Use of Surface Harmonic Tensors," ANL8081, February 1974, Argonne Nat. Lab., IL

[332] H.G. Kaper, G.K. Leaf and A.J. Lindeman, "Applications of Finite Element Methods in Reactor Mathematics. Numerical Solution of the Neutron Transport Equations," ANL-8126, October 1974, Argonne Nat. Lab., IL

[333] H.G. Kaper, G.K. Leaf and A.J. Lindeman, "Formulation of a Ritz-Galerkin Type Procedure for the Approximate Solution of the Neutron Transport Equation," $J$. Math. Anal. Applic., 50, 42-65 (1975)

[334] J. Katakura et al., "Development of the Computer Code System JACS for Criticality Safety," Trans. Am. Nucl. Soc., 41, 329-330 (1982)

[335] J. Katakura, "Development of Two- and Three-Dimensional Diffusion Codes 2DFEM and FEDM by Finite Element Method," Workshop Seminar on Finite Element Multidimensional Diffusion Codes, Saclay, France, September 15-16, 1983, published in Newsletter of the NEA Data Bank, No. 30, December 1983, pp 315334

[336] S. Katsimichas, C.R.E. de Oliveira and A.J.H. Goddard, "Hybrid Finite Element and Ray-Tracing Methods for Radiation Transport Problems with Voids," Proc. 1996 Topl. Mtg. Radiation Protection \& Shielding, N. Falmouth, MA, April 21-25, 1996, Vol 1, pp 307-313 
[337] A. Kavenoky, "NEPTUNE: A Modular Scheme for the Calculation of Light Water Reactors," Proc. Conf. Computational Methods in Nucl. Eng., April 15-17, 1975, Charleston, SC, Vol 2, pp V.27-V.41

[338] A. Kavenoky, "NEPTUNE: A Modular System for Light Water Reactor Calculations," Bulletin d'Informations Scientifiques et Techniques, 212, 7-19 (1976) (in French)

[339] A. Kavenoky and J.J. Lautard, "A Finite Element Depletion Diffusion Calculation Method with Space-Dependent Cross Sections," Nucl. Sci. Eng., 64, 563-575 (1977)

[340] A. Kavenoky and J.J. Lautard, "A Finite Element Depletion Diffusion Calculation Method With Space-Dependent Cross Sections," Nat. Topl. Mtg. on Improved Methods of Analysis of Nuclear Systems, March 28-30, 1977, Tuscon, AZ

[341] A. Kavenoky, J.J. Lautard, and P. Reuss, "Modeling of Feedback Effects: Development of the CRONOS Code," Trans. Am. Nucl. Soc., 32, 721-722 (1979)

[342] A. Kavenoky, J.J. Lautard, A. Manuel and D. Robeau, "NEPTUNE: ELECTRE and CRONOS for Power Distribution, Steady State and Transient Calculations Including Thermalhydraulic Negative Feedback," Proc. Specialists Mtg. on Calculation of 3-Dimensional Rating Distributions in Operating Reactors, November 26-28, 1979, Paris, France (NEACRP), pp 57-77

[343] A. Kavenoky and J.J. Lautard, "The Neutron Kinetics and Thermal Hydraulic Transient Computational Module of the Neptune System: CRONOS," Proc. ANS Top'l Mtg. Advances in Reactor Physics and Core Thermal Hydraulics, September 22-24, 1982, Kiamesha Lake, NY, Vol 2, pp 781-792

[344] A. Kavenoky and J.J. Lautard, "State of the Art in Using Finite Element Method for Neutron Diffusion Calculation," Proc. Topl. Mtg. Advances in Reactor Computations, March 28-31, 1983, Salt Lake City, UT, Vol 2, pp 963-986

[345] A. Kavenoky and J.J. Lautard, "Finite Element Computational Methods for Neutron Diffusion and Neutron Transport," Workshop Seminar on Finite Element Multidimensional Diffusion Codes, Saclay, France, September 15-16, 1983, published in Newsletter of the NEA Data Bank, No. 30, December 1983, pp 7-51

[346] A. Kavenoky and J.J. Lautard, "Acceleration and Vectorization Techniques for the Finite Element Diffusion Equation," Proc. Int. Mtg. on Advances in Nucl. Eng. Computational Methods, April 9-11, 1985, Knoxville, TN, Vol 1, pp 5-11

[347] A. Kavenoky and J.J. Lautard. "New Developments in Finite Element Reactor Calculations," Proc. Int. Seminar on Finite Element and Allied Methods for Reactor Physics and Shielding Calculations, September 18-20, 1985, London, England, published in Progress Nucl. Energy, 18, 3-6 (1986) 
[348] R.B. Kellogg, "Some Mathematical Aspects of Finite Element Calculations," Trans. Am. Nucl. Soc., 16, 131 (1973)

[349] S.A. Khaddaj, H. Al-Bahadili, A.J.H. Goddard, C.R.E. de Oliveira and J. Wood, "The Solution of Radiation Engineering Problems on a Transputer-Based System," Concurrency: Practice and Experience, 3, 423-434 (1991)

[350] H. Khouaja and D. Ray Edwards, "Spherical Harmonics - Finite Element Treatment of a Neutron Beam Transport in R-Z Geometry," Proc. 8th Int. Conf. on Radiation Shielding, April 24-28, 1994, Arlington, TX, pp 580-585

[351] H. Khouaja, D. Ray Edwards, and N. Tsoulfanidis, "Spherical Harmonics - Finite Element Treatment of Neutron Transport in Cylindrical Geometry," Ann. Nucl. Energy, 24, 515-531 (1997)

[352] F. Kikuchi, "A Finite Element Method for Non-Self-Adjoint Problems," Int. J. Num. Meth. Eng., 6, 39-54 (1973)

[353] C.H. Kim, J.H. Chang and D.H. Kim, "Finite Element Computation of Slab Criticality and Milne Problem," J. Korean Nucl. Soc., 8, 209-217 (1976)

[354] Y.I. Kim, J.K. Kim and S.D. Suk, "Finite Element Analysis of the Neutron Transport Equation in Spherical Geometry," J. Korean Nucl. Soc., 24, 319-328 (1992)

[355] A.D. Klimov, L.G. Strakhovskaya and R.P. Fedorenko, "Numerical Method of Calculating the Neutron Field in a Three-Dimensional Rectangular Cell of a Reactor," Zhurnal Vychislitel'noi Matematiki i Matematicheskoi Fiziki, 24, 10961101 (1984); translated in U.S.S.R. Computational Mathematics and Mathematical Physics, UK

[356] P. Kohut, "Anisotropic Eigenvalue Spectrum Calculations of the Neutron Transport Operator with Low-Order Spatial Expansion Methods," Nucl. Sci. Eng., 115, 320-333 (1993)

[357] H. Komoriya, An Energy-Dependent Finite Element Method for Reactor Analysis, PhD Dissertation, Univ. of Delaware, Newark, DE, 1976

[358] H. Komoriya and W.F. Walters, "Energy Dependent Finite Element Method for Two-Dimensional Diffusion Problems," Nat. Topl. Mtg. on Improved Methods of Analysis of Nuclear Systems, March 28-30, 1977, Tuscon, AZ; also as LA-UR-7759, Los Alamos Nat. Lab, NM

[359] H. Komoriya and W.F. Walters, "The Energy Dependent Finite Element Method for Two-Dimensional Diffusion Problems," Nucl. Sci. Eng., 64, 576-581 (1977)

[360] A.I. Kornilov and A.I. Popykin, "Numerical Solution of Two-Dimensional Equation in Diffusion Approximation by the Finite Element Method Eliminating the Peculiarities in Calulational Net Nodes," IAE-3617/16, 1982, Inst. Atomnoi Energii, Moscow, USSR (in Russian) 
[361] G.I. Kurchenkova, "Metod Galerkina dlya Diffuznykh Uravnenij," IAE-2522, 1975, Inst. Atomnoi Energii, Moscow, USSR (in Russian)

[362] V.V. Kuz'minov and I.S. Slesarev, "Combined Method of Elements in Solving the Gas Kinetic Equation of Neutron Transport," IAE-3450/5, 1981, Moscow Inst. Atomnoj Ehnergii, USSR (in Russian)

[363] J. Lang and A. Walter, "An Adaptive Discontinuous Finite Element Method for the Transport Equation," J. Comput. Phys., 117, 28-34 (1995)

[364] S. Langenbuch, W. Maurer, and W. Werner, "High-Order Schemes for Neutron Kinetics Calculations, Based on a Local Polynomial Approximation," Nucl. Sci. Eng., 64, 508-516 (1977)

[365] G. Lapenta, G.G. Coppa and P. Ravetto, "Validation of Angular Finite Element Techniques for Neutron Transport Calculations," Trans. Am. Nucl. Soc., 67, 397399 (1993)

[366] K.D. Lathrop, "Transport Theory Numerical Methods," Proc. Mathematical Models and Computational Techniques for Analysis of Nuclear Systems, April 9-11, 1973, Ann Arbor, MI, pp I-1-I-9

[367] K.D. Lathrop, "New Transport Methods and Codes," Advanced Reactors: Physics, Design and Economics, September 8-11, 1974, Atlanta, GA, pp 236-243

[368] J.J. Lautard, "New Finite Element Representation for 3-D Reactor Calculations" , Proc. Int. Topl. Mtg. Advances in Math. Methods for the Soln. of Nucl. Eng. Problems, April 27-29, 1981, Munich, FRG, Vol 1, pp 349-366

[369] J.J. Lautard, S. Loubiere and C. Fedon-Magnaud, "CRONOS: A Modular Computational System for Neutronic Core Calculations," Adv. Calculational Methods for Power Reactors and LWR Core Design Parameters, September 10-14, 1990, Cadarache, France, pp 42-50; published December 1992, IAEA-TECDOC-678, Int. Atomic Energy Agency

[370] J.J. Lautard and F. Moreau, "A Fast 3D Parallel Diffusion Solver Based on a Mixed Dual Finite Element Approximation," Joint Int. Conf. Mathematical Methods and Supercomputing in Nuclear Applications, MEC + SNA '93, April 19-23, 1993, Karlsruhe, Germany, Vol 2, pp 89-99

[371] G.K. Leaf, A.J. Lindeman and H.G. Kaper, "Construction of a Finite Element Approximation Which Crosses Material Interfaces," ANL-8052, January 1974, Argonne Nat. Laboratory, IL

[372] C. Lecot, "Sur L'Utilisation d'Elements Finis Angulaires pour la Resolution Numerique de L'Equation du Transport," CEA-N-2169, July 1980, CEA Centre d'Etudes de Limeil, 94-Villeneuve-Saint-Georges, France (in French) 
[373] L.W. Lee, Time-Dependent Transport-Equation Solver, Masters Thesis, Air Force Inst. Tech., Wright-Patterson AFB, OH, 1991

[374] P. Lesaint and P.A. Raviart, "On a Finite Element Method for Solving the Neutron Transport Equation," Mathematical Aspects of Finite Elements in Partial Differential Equations, C. de Boor (ed.), Academic Press, 1974, pp 89-123 (Proc. Symp. Univ. Wisconsin-Madison, April 1-3, 1974)

[375] P. Lesaint, "Finite Element Methods for the Transport Equation," RAIRO, R-2 $67-93,1974$

[376] P. Lesaint, "Continuous and Discontinuous Finite Element Methods for Solving the Transport Equation," The Mathematics of Finite Elements and Applications II, MAFELAP 1975, J.R. Whiteman (ed.), Academic Press, 1976, pp 151-161, (Proc. Conf. at Brunel Univ., England, April 1975)

[377] P. Lesaint, "Finite Element Methods for First Order Symmetric Hyberbolics," CEA-R-4731, February 1976, CEA Centre d'Etudes de Limeil, 94 - VilleneuveSaint-Georges, France (in French)

[378] P. Lesaint and P.A. Raviart, "Finite Element Collocation Methods for First Order Systems" Math. Computation, 33, 891-918 (1979)

[379] P. Lesaint, "Finite Element Methods for the Transport Equation," Proc. 1st European Graduate Summer Course on Computational Physics, Lausanne, Switzerland, September 1-10, 1986, published in Computer Physics Reports, 351 (1987) 351-369

[380] P. Lesaint and D. Verwaerde, "Etude sur les Relations Entre Methode Nodale et Methode Elements Finis Non Conformes," 91 NI J 0003, September 1991, EDFElectricite de France, Clamart, France (in French)

[381] E.E. Lewis and W.F. Miller, Jr., "Finite Element Integral Neutron Transport," Trans. Am. Nucl. Soc., 17, 237-238 (1973)

[382] E.E. Lewis, W.F. Miller Jr., and T.P. Henry, "A Two-Dimensional Finite Element Method for Integral Neutron Transport Calculations," Nucl. Sci. Eng., 58, 203$212(1975)$

[383] E.E. Lewis, "Finite Element Methods for Radiation Transport Calculations," Trans. Am. Nucl. Soc., 26, 474-475 (1977)

[384] E.E. Lewis, "Finite Element Approximation to the Even-Parity Transport Equation," Adv. Nucl. Sci. Technol., 13, 155-225 (1981)

[385] E.E. Lewis and H.A. Ozgener, "The Constrained Finite Element Approach to Coarse-Mesh Transport Computations," Proc. Int. Seminar on Finite Element Methods in Radiation Physics, April 23-24, 1981, London Univ., London, UK, published in Ann. Nucl. Energy, 8, 683-687 (1981) 
[386] E.E. Lewis and C.D. Swanson, "Comparison of Vector Computer Methods for the Solution of Slab Geometry Neutron Transport Problems," Proc. Topl. Mtg. Advances in Math. Meth. Soln. Nucl. Eng. Problems, April 27-29, 1981, Munich, F.R. Germany, Vol 2, pp 549-563

[387] E.E. Lewis and W.F. Miller, Jr., Computational Methods of Neutron Transport, 1984, John Wiley \& Sons, New York, pp 266-291

[388] E.E. Lewis and I. Dilber, "Finite Element, Nodal and Response Matrix Methods: A Variational Synthesis for Neutron Transport," Proc. Int. Seminar on Finite Element and Allied Methods for Reactor Physics and Shielding Calculations, September 18-20, 1985, London, England, published in Prog. Nucl. Energy, 18, 63-74 (1986)

[389] R.A. Lillie, Linear Triangle Finite Element Formulation for Multigroup Neutron Transport Analysis with Anisotropic Scattering, PhD Dissertation, Univ. of Tennessee, Knoxville, TN, 1976

[390] R.A. Lillie and J.C. Robinson, "A Linear Triangle Finite Element Formulation for Multigroup Neutron Transport Analysis with Anisotropic Scattering," ORNL/TM-5281, May 1976, Oak Ridge Nat. Lab., TN

[391] R.A. Lillie and J.C. Robinson, "A Discrete Angle, Finite Element Formulation," Trans. Am. Nucl. Soc., 26, 475-476 (1977)

[392] A.J. Lindeman, G.K. Leaf and H.G. Kaper, "A Computational Analysis and Evaluation of the Finite Element Method for a Class of Nuclear Reactor Configurations," Comp. Meth. Applied Mech. Eng., 4, 97-117 (1974)

[393] L. Lorence and W.R. Martin, "Response Matrix Finite Element Solution of the Neutron Transport Equation," Trans. Am. Nucl. Soc., 32, 305-306 (1979)

[394] L.J. Lorence Jr., Explicitly Interfaced Finite Element Solution of the Neutron Transport Equation, PhD Dissertation, Univ. Michigan, Ann Arbor, MI, 1984

[395] L.J. Lorence Jr., W.R. Martin and M. Luskin, "Analysis of a Block Gauss-Seidel Iterative Method for a Finite Element Discretization of the Neutron Transport Equation," Trans. Theory Stat. Phys., 14, 35-62 (1985)

[396] J.R. Maiorino and W.J. Vieira, "Application of Finite Element Method in the Solution of Transport Equation," Proc. 5th Nat. Mtg. Reactor Physics, April 10, 1985, Rio de Janeiro, Brazil, pp 207-226 (in Portuguese)

[397] A. Majumbar and W.R. Martin, "Parallel Preconditioned Conjugate Gradient Algorithm Applied to the Neutron Diffusion Problem," Trans. Am. Nucl. Soc., 65, 209-210 (1992)

[398] R.H. Mallett and R.K. Disney, "Current Finite Element Analysis Practices," Trans. Am. Nucl. Soc., 16, 131-132 (1973) 
[399] T. Manteuffel, S. McCormick, G. Yang, J. Morel and S. Oliveira, "A Parallel Version of a Multigrid Algorithm for Isotropic Transport Equations," SIAM J. Sci. Stat. Comp., 15, 474-493 (1994)

[400] G.I. Marchuk and V.I. Lebedev, Numerical Methods in the Theory of Neutron Transport, 2nd. Ed., 1986, Harwood Academic Publishers, New York, NY, Chapter VIII

[401] G. Marleau, R. Roy and A. Hebert, "Finite Element Solution to the Transport Equation," Proc. 15th Ann. Conf. Canadian Nucl. Soc., 1994, Toronto, Canada, Vol 1

[402] W.R. Martin, "Convergence of the Finite Element Method in Neutron Transport," Trans. Am. Nucl. Soc., 22, 251-252 (1975)

[403] W.R. Martin, Application of the Finite Element Method to the Neutron Transport Equation, PhD Dissertation, Univ. Michigan, Ann Arbor, MI, 1976

[404] W.R. Martin and J.J. Duderstadt, "Finite Element Solutions of the Neutron Transport Equation with Applications to Strong Heterogeneities," Nucl. Sci. Eng., 62, 371-390 (1977)

[405] W.R. Martin, C.E. Yehnert, L. Lorence and J.J. Duderstadt, "Phase-Space Finite Element Methods Applied to the First-Order Form of the Transport Equation," Proc. Int. Seminar on Finite Element Methods in Radiation Physics, April 23-24, 1981, London Univ., London, UK, published in Ann. Nucl. Energy, 8, 633-646 (1981)

[406] V. Mastrangelo, "Three-Dimensional Model of Neutronic-Thermo-Hydrodynamic Interaction in the Core of Light Water Reactors (Stationary State)," Atomkernenerg./Kerntech, 34, 3-10 (1979) (in French)

[407] P. Matejovic and V. Adamik, "A Diffusion Equation with Hourglass Control in an Axisymmetric Geometry," Comput. Meth. Appl. Mech. Eng., 76, 135-156 (1989)

[408] K.A. Mathews, "Discrete Elements Method of Neutron Transport," Nucl. Sci. Eng., 98, 41-50 (1988)

[409] K.A. Mathews, "Adaptive Characteristic Spatial Quadratures for Discrete Ordinates Neutral Particle Transport - The Slab Geometry Case," Transp. Theory Stat. Physics, 19, 419-458 (1990)

[410] G. Mathonniere, Study of Neutronic Problems Related to the Xenon Instability in the Pressurized Water Reactor, DSci Thesis, CEA-N-2556, CEA Centre d'Etudes Nucleaires de Saclay, 91 - Gif-sur-Yvette, France, March 1988 (in French)

[411] D.R. McCoy, E.E. Lewis, M.J. Lee, L.L. Briggs and R.N. Blomquist, "The Inclusion of Buckling Approximations in Finite Element Neutron Transport Methods," Trans. Am. Nucl. Soc., 26, 226-227 (1977) 
[412] P.J. McDaniel, P.C. Lysne and J.M. Harris, "Application of the FEMP Codes to Well Logging Problems," Trans. Am. Nucl. Soc., 54, 154 (1987)

[413] J.M. McGhee, R.M. Roberts, and J.E. Morel, "The DANTE Boltzman Transport Solver: An Unstructured Mesh, 3-D, Spherical Harmonics Algorithm Compatible with Parallel Computer Architectures," Proc. Joint Int. Conf. Mathematical Methods and Supercomputing for Nuclear Applications, October 5-9, 1997, Saratoga Springs, NY, Vol 1, pp 563-572

[414] D. Meade, Collocation Methods for Space-Time Nuclear Reactor Dynamics, PhD Disseration, University of California, Berkeley, 1982

[415] D. Meade, "Solution of the Neutron Group-Diffusion Equations by Orthogonal Collocation with Cubic Hermite Interpolants," Trans. Theory Stat. Phys., 12, 271-284 (1983)

[416] Y. Mederbel, "Resolution de l'Equation du Transport du Zeme Ordre par Application de la Methode des Elemẹnts Finis sur l'Espace des Phases," FRNC-TH-751, 1977, Paris-11 Univ., 91 - Orsay, France

[417] J. Mika, "New Methods in Linear Transport Theory. Part of a Coordinated Programme on Methods in Neutron Transport Theory. Final Report for the Period 1 August 1972 - 31 July 1974," IAEA-R-1236-F, September 1975, Int. Atomic Energy Agency, Vienna

[418] W.F. Miller Jr., E.E. Lewis and E.C. Rossow, "Transport Solutions Using Finite Elements in Space-Angle Phase Space,". Trans. Am. Nucl. Soc., 14, 651-652 (1971)

[419] W.F. Miller Jr., E.E. Lewis and E.C. Rossow, "Two-Dimensional Transport Calculations Using Phase-Space Finite Elements," Trans. Am. Nucl. Soc., 15, 780-781 (1972)

[420] W.F. Miller Jr., E.E. Lewis and E.C. Rossow, "The Application of Phase-Space Finite Elements to the One-Dimensional Neutron Transport Equation," Nucl. Sci. Eng., 51, 148-156 (1973)

[421] W.F. Miller Jr., E.E. Lewis and E.C. Rossow, "The Application of Phase-Space Finite Elements to the Two-Dimensional Neutron Transport Equation in X-Y Geometry," Nucl. Sci. Eng., 52, 12-22 (1973)

[422] W.F. Miller Jr. and E.E. Lewis, "Quadratic Finite Elements in Neutron Transport," Trans. Am. Nucl. Soc., 17, 235 (1973)

[423] W.F. Miller Jr., Application of Finite-Elements to One-Dimensional and Two-Dimensional Neutron-Transport, PhD Dissertation, Northwestern Univ., Evanston, IL, 1973

[424] W.F. Miller Jr., "Transport and Reactor Theory. Progress Report, April 1 - June 30, 1976," LA-6437-PR, August 1976, Los Alamos Scientific Lab., NM 
[425] W.F. Miller Jr. and T. Noh, "Finite Differences versus Finite Elements in Slab Geometry, Even-Parity Transport Theory," Transp. Theory Stat. Physics, 22, 247-270 (1993)

[426] D. Ming-Sheng and F. Shang-Wu, "The Two-Directional Discontinuous Finite Element Method for Solving the Transport Problem," Chinese J. Num. Meth. \& Appl., 10, 28-38 (1988), also J. Num. Meth. Comp. Appl., 7, 158-168 (1986)

[427] D. Ming-Sheng, F. Tiekai, F. Lianxiang, C. Changshu and L. Yulan, "Numerical Method for Two-Dimensional Anisotropic Transport Problem in Cylindrical Geometry," Chinese J. Comput. Phys., 4, 401-412 (1988) (in Chinese)

[428] I. Misfeldt, "Solution of the Multigroup Neutron Diffusion Equations by the Finite Element Method," RISO-M-1809, July 1975, Danish Atomic Energy Comm., Risoe, Roskilde, Denmark

[429] I. Misfeldt, "Program FEMB Users Manual," RISO-M-1929, March 1977, Research Establishment Risoe, Rosklide, Denmark

[430] I. Misfeldt, "The Program FEM2B Users Manual," RISO-M-1969, November 1977, Risoe National Lab., Roskilde, Denmark

[431] M. Mordant, "ZEPHYR: A New Finite Element Transport Code for General TwoDimensional Geometries," Trans. Am. Nucl. Soc., 24, 187 (1976)

[432] M. Mordant, "Some Efficient Lagrangian Mesh Finite Elements Encoded in ZEPHYR for Two-Dimensional Transport Calculations," Proc. Int. Seminar on Finite Element Methods in Radiation Physics, April 23-24, 1981, London Univ., London, UK, published in Ann. Nucl. Energy, 8, 657-675 (1981)

[433] M. Mordant, "New Phase Space Finite Element Transport Solutions," Proc. Topl. Mtg. Advances in Reactor Computations, March 28-31, 1983, Salt Lake City, UT, Vol 2, pp 782-795

[434] M. Mordant, "Linear Discontinuous Finite Elements for Phase Space Multidimensional Transport Calculations," Proc. Int. Mtg. on Advances in Nucl. Eng. Computational Methods, April 9-11, 1985, Knoxville, TN, Vol II, pp 501-514

[435] M. Mordant, "Phase-Space Finite Elements Encoded in ZEPHYR for X-Y and R-Z Transport Calculations," Proc. Int. Seminar on Finite Element and Allied Methods for Reactor Physics and Shielding Calculations, September 18-20, 1985, London, England, published in Prog. Nucl. Energy, 18, 27-37 (1986)

[436] M. Mordant, "Linear Discontinuous Finite Elements for Phase-Space Multidimensional Transport Calculations," Nucl. Sci. Eng., 92, 218-227 (1986)

[437] M. Mordant, "Discontinous Finite Element Methods for Solving the First Order Transport Equation," Int. Topl. Mtg. on Advances in Reactor Physics, Mathematics and Computation, April 27-30, 1987, Paris, France, Vol 3, pp 1401-1412 
[438] 'J.E. Morel, "Collocation Method for the Solution of the Neutron Transport Equation with Both Symmetric and Asymmetric Scattering," SAND-80-1446, January 1981, Sandia Nat. Labs, Albuquerque, NM

[439] J.E. Morel, L.A. Olvey, J.M. McGhee, G.W. Claborn and J.A. Josef, "DiffusionAccelerated Solution of the Even-Parity $S_{N}$ Equations with Anistropic Scattering," Int. Topl. Mtg. Advances in Mathematics, Computations, and Reactor Physics, April 28-May 2, 1991, Pittsburgh, PA, Vol 3, pp 11.2 3-1-11.2 3-10

[440] J.E. Morel, J.E. Dendy Jr., and T.A. Wareing, "Diffusion-Accelerated Solution of the Two-Dimensional $S_{n}$ Equations with Bilinear-Discontinuous Differencing," Nucl. Sci. Eng., 115, 304-319 (1993)

[441] J.E. Morel, J.E. Dendy Jr., and T.A. Wareing, "Diffusion-Accelerated Solution of the 2-D $S_{N}$ Equations with Bilinear-Discontinuous Differencing," Int. Topl. Mtg. Mathematical Meth. and Supercomputing in Nucl. Appl. (MC+SNA '93), April 19-23, 1993, Karlsruhe, Germany, Vol 2, pp 488-499

[442] J.E. Morel, J.M. McGhee and W.F. Walters, "3-D Research Transport Codes at Los Alamos," Proc. Int. Conf. Math. and Comp., Reactor Physics, and Env. Analyses, April 30-May 4, 1995, Portland, OR, Vol 1, pp 527-533

[443] J.E. Morel, J.M. McGhee and E.W. Larsen, "A 3-D Time-Dependent Unstructured Tetrahedral-Mesh $S P_{N}$ Method," Proc. Int. Conf. Math. and Comp., Reactor Physics, and Env. Analyses, April 30-May 4, 1995, Portland, OR, Vol 2, pp 887-896, also published in Nucl. Sci. Eng., 123, 319-327 (1996)

[444] M. Mus, "Neutron Diffusion Theory Flux Calculation by Finite Element Method," UTC-76-35, Universite de Technologie de Compiegne, 60, France, 1976 (in French)

[445] B.C. Na and J. K. Kim, "Effectiveness of the Discrete Elements Method for the Slab-Geometry Neutron Transport Equation," J. Korean Nucl. Soc., 22, 151-158 (1990)

[446] Y. Naito, S. Tsuruta and M. Hayashi, "A New Mixed Method with Finite Difference and Finite Element Method for Neutron Diffusion Calculation," J. Nucl. Sci. Technol., 18, 571-580 (1981)

[447] Y. Naito, R. Kawamura, Y. Tokuno and S. Tsuruta, "A Computer Program for Solving the Three-Dimensional Multigroup Diffusion Equation by the Finite Element Method with 20-Node Isoparametric Element (FEM3DJAR)," Proc. Int. Seminar on Finite Element and Allied Methods for Reactor Physics and Shielding Calculations, September 18-20, 1985, London, England, published in Prog. Nucl. Energy, 18, 207-214 (1986)

[448] Y. Nakahara, et al., "Retrospective and Prospective Survey of Three-Dimensional Transport Calculations," Proc. Seminar on Software Development in Nuclear Energy Research, September 27, 1984, Tokai, Ibaraki, Japan, pp 5-11 (in Japanese) 
[449] S. Nakamura and T. Ohnishi, "A Study of Iterative Solutions for the Finite Element Method," Trans. Am. Nucl. Soc., 14, 662 (1971)

[450] S. Nakamura and T. Ohnishi, "The Iterative Solutions for the Finite Element Method," Proc. Seminar on Numerical Reactor Calculations, January 17-21, 1972, Vienna, Int. Atomic Energy Agency, pp 639-656

[451] H. Nakata and W.R. Martin, "The Finite Element Response Matrix Method for Coarse-Mesh Calculations," Trans. Am. Nucl. Soc., 39, 464-465 (1981)

[452] H. Nakata and W.R. Martin, "The Finite Element Response Matrix Method," Nucl. Sci. Eng., 85, 289-305 (1983)

[453] M.M. Nanneh and R.T. Ackroyd, "Hybrid Principle with Applications to Synthesis," 3rd Int. Seminar on Finite Element and Allied Methods in Radiation Transport: Shielding, Reactor Physics, and Geophysics Applications, April 19-20, 1990, Imperial College, London, UK, published in Prog. Nucl. Energy, 25:2/3 (1991) $199-208$

[454] M.M. Nanneh, R.T. Ackroyd, J.G. Issa and N.S. Riyait, "Projection and Conservation Methods for Neutron Transport," Aalam Al-Zarra (The World of Atom), 11, 75-77 (1990) (In Arabic)

[455] R.S. Naoum and P.K. Mahanti, "On the Error Estimates of the Approximate Solution of Stationary Neutron Transport Equation By Finite Element Method," An. Univ. Craiova Mat. Fiz.-Chim., 4, 22-26 (1976)

[456] D.H. Nguyen and D. Salinas, "Finite Element Solutions of Space-Time Nonlinear Reactor Dynamics," Nucl. Sci. Eng., 60, 120-130 (1976)

[457] A. Nicolas, "Calculation and Utilization of Albedos for PWR Core Analysis in Transport and Diffusion Theories," Int. Conf. Physics of Reactors: Operation, Design and Computation, Physor 90, April 23-27, 1990, Marseille, France, Vol 3, PIV.87-PIV.95

[458] S. Nisan, P. Hammer, J.J. Lautard and M. Mus, "Comparison of Spatial Calculation Methods for Fast Reactors," Proc. Int. Symp. Fast Reactor Physics, September 24-28, 1979, Aix en Provence, France, Vol 2, pp 371-381 (in French)

[459] T. Noh, W.F. Miller Jr. and J.E. Morel, "Improved Approximations Applied to the $S_{N}$ Even-Parity Equations," Trans. Am. Nucl. Soc., 69, 214-215 (1993)

[460] T. Noh, W.F. Miller Jr. and J.E. Morel, "The Even-Parity and Simplified EvenParity Transport Equations in Two-Dimensional $x-y$ Geometry," Nucl. Sci. Eng., 123, 38-56 (1996)

[461] R.D. O'Dell, J. Stepanek and M.R. Wagner, "Intercomparison of the Finite Difference and Nodal Discrete Ordinates and Surface Flux Transport Methods for a LWR Pool Reactor Benchmark Problem in X-Y Geometry," Proc. Topl. Mtg. 
Advances in Reactor Computations, March 28-31, 1983, Salt Lake City, UT, Vol 2 , pp $757-781$

[462] T. Ohnishi, "Application of Finite Element Solution Technique to Neutron Diffusion and Transport Equations," Proc. Conf. New Developments in Reactor Mathematics and Applications, March 29-31, 1971, Idaho Falls, ID, pp 723-738

[463] T. Ohnishi, "Finite Element Method Applied to Reactor Physics Problems," J. Nucl. Sci. Tech., 8, 717-720 (1971)

[464] T. Ohnishi, "Finite-Element Solution Technique for Neutron Transport Equations ( $F_{N}$ Approximation)," Proc. Seminar on Numerical Reactor Calculations, January 17-21, 1972, Vienna, Int. Atomic Energy Agency, pp 629-638

[465] A. Onana, S.Y. Kwankam and M.N. Joseph, "Solution of the Two-Dimensional Neutron Transport Equation by the Hierarchical Finite Element Method," Int. J. Num. Meth. Heat and Fluid Flow, 3, 35-47 (1993)

[466] S. Ono and J.R. Maiorino, "Application of the Finite Element Method in the Solution of Steady State Diffusion Equation," Proc. 4th Brazilian Mtg. Reactor Physics, November 3, 1983, Itaipava, RJ, Brazil, pp 5-17, INIS-br-260 (in Portuguese)

[467] A. Oukebdane and W.R. Martin, "Coarse-Mesh Heterogeneous Response Matrix Method for Reactor Analysis," Trans. Am. Nucl. Soc., 64, 280-281 (1991)

[468] B. Ozgener and H.A. Ozgener, "A Study of the Consistent and the Lumped Source Approximations in the Finite Element Neutron Diffusion Calculations," 3rd Int. Seminar on Finite Element and Allied Methods in Radiation Transport: Shielding, Reactor Physics, and Geophysics Applications, April 19-20, 1990, Imperial College, London, UK, published in Prog. Nucl. Energy, 25, 209-215 (1991)

[469] B. Ozgener, "A Comparison of the Lumped and Consistent Source Treatments in 3-D Finite-Element Diffusion Calculations," Ann. Nucl. Energy, 17, 427-433 (1990)

[470] B. Ozgener and H.A. Ozgener, "The Solution of the Criticality Eigenvalue Problems in Application of the Boundary Element Method to the Neutron Diffusion Equation," Ann. Nucl. Energy, 20, 503-518 (1993)

[471] B. Ozgener and H.A. Ozgener, "The Application of the Multiple Reciprocity Method to the Boundary Element Formulation of the Neutron Diffusion Equation," Ann. Nucl. Energy, 21, 711-723 (1994)

[472] H.A. Ozgener and E.E. Lewis, "Multigroup Criticality Calculations for NonUniform Lattices Using a Constrained Finite Element Method," Trans. Am. Nucl. Soc., 35, 235-236 (1980) 
[473] H.A. Ozgener, A Heterogeneous Solution Technique for Nonuniform Lattice Problems in Neutron Transport, PhD Dissertation, Northwestern Univ., Evanston, IL, 1981

[474] T.S. Palmer and M.L. Adams, "Analysis of Spherical Geometry Finite Element Transport Solutions in the Thick Diffusion Limit," Proc. Int. Topl. Mtg. Advances in Math., Comp., and Reactor Phys., April 28-May 2, 1991, Pittsburgh, PA, Vol 5 , pp $21.14-1-4-11$

[475] T.S. Palmer and M.L. Adams, "Curvilinear Geometry Transport Discretizations in the 'Thick' Diffusion Limit," Joint Int. Conf. Mathematical Methods and Supercomputing in Nuclear Applications, $M E C+S N A$ '93, April 19-23, 1993, Karlsruhe, Germany, Vol 1, pp 3-14

[476] S. Pelloni, "Solution of Finite Element Problems Without Assembly Using Group Theory," Proc. Int. Seminar on Finite Element Methods in Radiation Physics, April 23-24, 1981, London Univ., London, UK, published in Ann. Nucl. Energy, 8, 621-632 (1981)

[477] S. Pelloni, C. Higgs and D. Davierwalla, "FINELM: A Multigroup Finite Element Diffusion Code, III. R- $\theta$ Geometry and Internal Boundary Conditions," EIR-459, April 1982, Eidgenoessisches Inst. fuer Reaktorforschung, Wuerenlingen, Switzerland

[478] S. Pelloni, "Possible Future FINELM Developments," Workshop Seminar on Finite Element Multidimensional Diffusion Codes, Saclay, France, September 15-16, 1983, published in Newsletter of the NEA Data Bank, No. 30, December 1983, pp 260-286

[479] I. Petrovicj, "Application of the Finite Element Method to the Multigroup TwoDimensional Neutron Diffusion Equation on the KONEL Code," Proc. 30th Conf. Electronics, Telecommunications, Automation and Nucl. Eng., June 2, 1986, Herceg Novi, Yugoslavia, pp 169-176 (in Serbo-Croat)

[480] J. Pitkaranta and P. Silvennoinen, "Computational Experimentation on the Finite Element Method in Bare Slab Criticality Calculations," Nucl. Sci. Eng., 50, 297$300(1973)$

[481] J. Pitkaranta and P. Silvennoinen, "Vacuum Description in Symmetrized Transport Calculations," Trans. Am. Nucl. Soc., 17, 235-236 (1973)

[482] J. Pitkaranta and P. Silvennoinen, "Finite Element Analysis of Some Critical Fast Assemblies," Nucl. Sci. Eng., 52, 447-453 (1973)

[483] J. Pitkaranta, "Finite Element Solution of the Multigroup Transport Equation in Two-Dimensional Geometries," Acta Polytech. Scand. Phys. Nucl. Ser., 101, 1-33 (1974) 
[484] J. Pitkaranta, "A Non-Self-Adjoint Variational Procedure for the Finite Element Approximation of the Transport Equation," Trans. Theory Stat. Physics, 4, 1-24 (1975)

[485] J. Pitkaranta, "Properties of Transport Solution for Neutron Density in Slab Geometry in Piecewise Polynomial Approximation," J. Nucl. Sci. Technol., 13, 715721 (1976)

[486] E. Pohlen, "Investigation of Core Neutronics Calculational Methods for the HTRCritical Experiment (KAHTER) with Regard to the Validity of Calculation of the Influence of the Upper Cavity," Juel-1760, January 1982, Kernforschungsanlage Juelich G.m.b.H., F.R. Germany (in German)

[487] R.A. Price, S. Katsimichas, C.R.E. de Oliveira and A.J.H. Goddard, "Mixed Finite Elements and MCNP Treatment in Highly Scattering Deep Penetration Problems," Proc. 1996 Topl. Mtg. Radiation Protection 8 Shielding, N. Falmouth, MA, April 21-25, 1996, Vol 1, pp 314-321

[488] M.D. Purwadi, M. Tsuji, and M. Narita, "A Higher Harmonics Analysis of 3D Neutron Diffusion Equation Using the Hierarchical Domain Decomposition Boundary Element Method," J. Nucl. Sci. Tech., 33, 741-743 (1996)

[489] C.S. Quah, "A Comparison of Finite Elements and Discrete Ordinate Methods for One-Dimensional Multigroup Problems," Proc. Int. Seminar on Finite Element Methods in Radiation Physics, April 23-24, 1981, London Univ., London, UK, published in Ann. Nucl. Energy, 8, 709-715 (1981)

[490] C.S. Quah, J.G. Issa, A.J.H. Goddard and R.T. Ackroyd, "FELTRAN," The Mathematics of Finite Elements and Applications - MAFELAP V, J.R. Whiteman (ed.), Academic Press, London, (1985)

[491] J.A. Rathkopf and W.R. Martin, "A Coarse-Mesh Transport Theory Response Matrix Method," Trans. Am. Nucl. Soc., 46, 403-405 (1984)

[492] J.A. Rathkopf, Finite Element Response Matrix Method for the Solution of the Transport Equation, PhD Dissertation, Univ. Mich., Ann Arbor, MI, 1984

[493] J.A. Rathkopf and W.R. Martin, "The Finite Element Response Matrix Method for the Solution of the Neutron Transport Equation," Proc. Int. Seminar on Finite Element and Allied Methods for Reactor Physics and Shielding Calculations, September 18-20, 1985, London, England, published in Prog. Nucl. Energy, 18, 237-250 (1986)

[494] J.A. Rathkopf and W.R. Martin, "A Transport Theory Response Matrix Method in Two Dimensions," Trans. Am. Nucl. Soc., 53, 286-288 (1986)

[495] J.A. Rathkopf, L.J. Lorence and W.R. Martin, "The Explicitly-Interfaced Method and the Response Matrix Method: Two Methods for the Solution of the Transport 
Equation," Int. Topl. Mtg. on Advances in Reactor Physics, Mathematics and Computation, April 27-30, 1987, Paris, France, Vol 2, pp 1021-1031

[496] W.H. Reed, T.R. Hill, F.W. Brinkley and K.D. Lathrop, "TRIPLET: A TwoDimensional, Multigoup, Triangular Mesh, Planar Geometry, Explicit Transport Code," LA-5428-MS, 1973, Los Alamos Scientific Lab., New Mexico

[497] N.S. Riyait and R.T. Ackroyd, "The Finite-Element Method for Multigroup Neutron Transport: Anisotropic Scattering in 1-D Slab Geometry," Ann. Nucl. Energy, 14, 113-133 (1987)

[498] M.A. Robinson and R.A. Rydin, "An Improved Polynomial Coarse-Mesh Method Based on Modified Finite Elements," Trans. Am. Nucl. Soc., 38, 349-351 (1981)

[499] P.E. Rohan, C.M. Kang, R.A. Shober and S.G. Wagner, "Multi-Dimensional Space-Time Kinetics Code for PWR Transients," Proc. Conf. Computational Methods in Nucl. Eng., April 15-17, 1975, Charleston, SC, Vol 2, pp VI.69-VI.83

[500] P.E. Rohan, S.G. Wagner and S.E. Ritterbusch, "HERMITE: A Multi-Dimensional Space-Time Kinetics Code for PWR Transients," CENPD-188-A, July 1976, Combustion Eng. Inc., Windsor, CT

[501] W. Rothenstein, C.R.E. de Oliveira and N. Brandman, "Accurate Resonance Absorption Calculations Including 2-D Effects and Their Representation in Multigroup Lattice Physics Codes," Ann. Nucl. Energy, 15, 293-316 (1988)

[502] W. Rothenstein, "Convergence of Finite Element Transport Calculations for the Analysis of Reactor Lattices," Trans. Nucl. Soc. Israel Ann. Mtg. 1989, March 13, 1989, pp 40-44

[503] W. Rothenstein and C.R.E de Oliveira, "Discrete Energy or Multigroup Finite Element Transport Calculations in Lattice Physics," 3rd Int. Seminar on Finite Element and Allied Methods in Radiation Transport: Shielding, Reactor Physics, and Geophysics Applications, April 19-20, 1990, Imperial College, London, UK, published in Prog. Nucl. Energy, 25, 107-126 (1991)

[504] W. Rothenstein and C.R.E de Oliveira, "Convergence of Finite Element Calculations of Shielding Factors in Multigroup Reactor Analysis," Int. Conf. Physics of Reactors: Operation, Design and Computation, Physor 90, April 23-27, 1990, Marseille, France, Vol 3, PII.28-PII.37

[505] W. Rothenstein, "Finite Element Neutron Transport Calculations in Lattice Physics: Convergence Characteristics," Nucl. Soc. Israel Trans., Vol 16, December 17-18, 1990, Herzliya, Israel, pp 49-52

[506] B. Rousselet, "Optimal Design and Eigenvalue Problems," Proc. 8th IFIP Conf. Optimization Techniques, September 5-9, 1977, Wurzburg, W. Germany, Part 1, pp 343-352 
[507] D. Ruan, Ch. De Raedt and F. Zhang, "Development Work Currently Being Carried Out on the Time-Dependent Finite-Element Diffusion Code TRANSFUSION for Nuclear Oil Well Logging Problems," Joint Int. Conf. Mathematical Methods and Supercomputing in Nuclear Applications, $M B C+$ SNA '93, April 19-23, 1993, Karlsruhe, Germany, Vol 1, pp 81-92

[508] R. Ruhle, "RSYST, ein Integriertes Modulsystem mit Datenbasis zur Automatischen Berechnung von Kernreaktoren," IKE-4-12, 1973, Inst. fuer Kernenergetik und Energiesysteme, FRG (in German)

[509] M.A. Salehi, Analysis of Non-Linear Feedback in Space-Time Reactor Dynamics of Finite-Element Methods, PhD Dissertation, Univ. California at Berkeley, CA, 1983

[510] G. Samba, "Resolution of the Steady State Transport Equation for Lagrangian Geometry with Cylindrical Symmetry," CEA-N-2365, CEA Centre d'Etudes de Limeil, 94 - Villeneuve-Saint-Georges, France, May 1983 (in French)

[511] G. Samba, "Discontinous Finite Element Method for Solving the Two-Dimensional Neutron Transport Equation on Lagrangian Meshes," Proc. Int. Mtg. on Advances in Nucl. Eng. Computational Methods, April 9-11, 1985, Knoxville, TN, Vol II, pp 461-472

[512] G.Samba, "Discontinuous Finite Element Method for Solving the Two-Dimensional Neutron Transport Equation on Lagrangian Meshes," Nucl. Sci. Eng., 92, 197-203 (1986)

[513] C.A. Sanchez, "Solution of the Diffusion Equations for Various Groups by the Finite Element Method," NP-20592, July 1975, Instituto Politecnico Nacional, Mexico City, Mexico (in Spanish)

[514] R. Sanchez and N.J. McCormick, "Review of Neutron Transport Approximations," Nucl. Sci. Eng., 80, 481-535 (1982)

[515] E. Sapper, "Verfahren zur Optimalen Anwendung der Finite-Elemente-Methode bei der Berechnungen Reaktorphysikalischer Probleme," IKE-4-55, May 1976, Inst. fuer Kernenergetik und Energiesysteme, FRG (in German)

[516] V.A. Sarychev and V.G. Fen, "Calculation of the Neutron Field in HTGR by the Finite Element Method With Using the Response Matrices For the Effective Evaluation of the Control Rods Influence," Problems of Nuclear Science and Technology, A. Y. Gagarinski (ed.), 1992, pp 27-31 (in Russian)

[517] J. Schmid and J. Cermak, "Multigroup Fast Reactor Calculation by Finite Element Method. IV. Computer Programs," UJV-4490-A, March 1978, Ustav Jaderneho Vyzkumu CSKAE, Rez, Czechoslovakia, (in Czech) 
[518] J. Schmid, "Two-Dimensional Multigroup Finite Element Calculation of Fast Reactor in Diffusion Approximation," UJV-7682-T, June 1986, Ustav Jaderneho Vyzkumu CSKAE, Rez, Czechoslovakia, (in Czech)

[519] F.A.R. Schmidt and H.P. Franke, "Finite Element vs. Finite Differences - A Comparison of Two Possible Ways of Solving the Diffusion Equation," Proc. Reactor Engineering 1973, April 10-13, 1973, Karlsruhe, W. Germany, pp 47-50

[520] F.A.R. Schmidt, "FEM-2D - Input Description and Performance," IKE-4-43, March 1975, Inst. fuer Kernenergetik und Energiesysteme, FRG

[521] F.A.R. Schmidt and H.P. Franke, "Power Reactor Calculations with the Finite Element Program FEM 2D," Nucl. Sci. Eng., 56, 431-433 (1975)

[522] F.A.R. Schmidt, H.P. Franke and E. Sapper, "On the Application of the Finite Element Method in Reactor Physics," The Mathematics of Finite Elements and Applications II, MAFELAP 1975, 1976, Academic Press (Proc. of Conf. held in April 1975, Brunel Univ., England), pp 391-398

[523] F.A.R. Schmidt, H. Ambrosius, H.P. Franke, E. Sapper, and M.R. Wagner, "Experiences with the Finite Element Method for Standard Reactor Calculations," Proc. Conf. Computational Methods in Nucl. Eng., April 15-17, 1975, Charleston, $\mathrm{SC}, \mathrm{Vol} 1$, pp I.53-I.69

[524] F. Schmidt, R. Fremd and D. Woerner, "Finite Element Calculations on the 3D HTGR Benchmark Problem," Reactor Congress, April 4-7, 1978, Hannover, FRG, pp 7-10 (in German)

[525] F.A.R. Schmidt, R. Fremd, H. Pflieger and D. Worner, "Two- and Three-Dimensional Reactor Physics Calculations for HTR Reactors with the Finite Element Method," Proc. ANS Topl. Mtg. on Advances in Reactor Physics, April 10-12, 1978, Gatlinburg, TN, pp 399-409

[526] F.A.R. Schmidt, "Finite Element Methods for the Solution of Multidimensional Reactor Physics Problems," IKE-4-88, March 1979, Inst. fuer Kernenergetik und Energiesysteme, FRG

[527] F. Schmidt and R. Fremd, "Experience in Using the Finite Element Method for Reactor Calculations," Proc. Int. Seminar on Finite Element Methods in Radiation Physics, April 23-24, 1981, London Univ., London, UK, published in Ann. Nucl. Energy, 8, 567-580 (1981)

[528] F.A.R. Schmidt, "Finite Element Application to Global Reactor Analysis," Proc. Int. Topl. Mtg. Advances in Math. Methods for the Soln. of Nucl. Eng. Problems, April 27-29, 1981, Munich, FRG, Vol 1, pp 315-334

[529] F. Schmidt, P.R. Mayer, G. Frey and W. Gieber, "Experiences in Solving the Neutron Diffusion Equation by the Finite Element Method on a Cray-1, Proc. 
Int. Mtg. on Advances in Nucl. Eng. Computational Methods, April 9-11, 1985, Knoxville, TN, Vol 1, pp 12-21

[530] F. Schmidt, "Solution of the Neutron Diffusion Equation by the Finite Element Method," Kerntechnik, 57, 223-227 (1992)

[531] F. Schmidt, "Solution of the Neutron Diffusion Equation by the Finite Element Method - Foundations and Practical Experience," IKE-4-138, March 1994, Inst. fuer Kernenergetik und Energiesysteme, Stuttgart Univ., Germany (in German)

[532] F. Schmittroth and R.E. Schenter, "Finite Element Basis in Data Adjustment," Nucl. Sci. Eng., 74, 168-177 (1980)

[533] S.L. Schofield and M. Pourzand, "Single-Pass Treatment of Voids in F.E. Transport Theory," 3rd Int. Seminar on Finite Element and Allied Methods in Radiation Transport: Shielding, Reactor Physics, and Geophysics Applications, April 19-20, 1990, Imperial College, London, UK, published in Prog. Nucl. Energy, 25, 217-229 (1991)

[534] B. Schwab and F. Schmidt, "Application of Internal Nodes on Using Finite Elements in Reactor Physics," IKE-4-70, February 1977, Inst. fuer Kernenergetik und Energiesysteme, FRG (in German)

[535] T.J. Seed and R.W. Albrecht, "The Walsh Function Approximation for Neutron Transport in X-Y Geometry," Trans. Am. Nucl. Soc., 21, 227-228 (1975)

[536] T.J. Seed, W.F. Miller Jr. and F.W. Brinkley Jr., "TRIDENT: A TwoDimensional, Multigroup, Triangular Mesh Discrete Ordinates, Explicit Neutron Transport Code," LA-6735-M, March 1977, Los Alamos Nat. Labs., NM

[537] T.J. Seed, W.F. Miller Jr. and G.E. Bosler, "TRIDENT: A New Triangular Mesh Discrete-Ordinates Code," Proc. ANS Top'l Mtg. on Advances in Reactor Physics, April 10-12, 1978, Gatlinburg, TN, pp 157-167; also LA-UR-77-2511, Los Alamos Nat. Labs, NM

[538] L.A. Semenza, E.E. Lewis and E.C. Rossow, "A Finite Element Treatment of Neutron Diffusion," Trans. Am. Nucl. Soc., 14, 200-201 (1971)

[539] L.A. Semenza, E.E. Lewis and E.C. Rossow, "Dual Finite Element Methods for Neutron Diffusion," Trans. Am. Nucl. Soc., 14, 662-664 (1971)

[540] L.A. Semenza, Application of the Finite Element Method to Two Dimensional Multigroup Neutron Diffusion, PhD Dissertation, Northwestern Univ., Evanston, IL, 1972

[541] L.A. Semenza, E.E. Lewis and E.C. Rossow, "The Application of the Finite Element Method to the Multigroup Neutron Diffusion Equation," Nucl. Sci. Eng., 47, 302-310 (1972) 
[542] L.A. Semenza, E.E. Lewis and E.C. Rossow, "Finite Element Neutron Diffusion in Curvilinear Coordinates," Trans. Am. Nucl. Soc., 15, 780 (1972)

[543] F. Shangwu, "The Two Dimensional Discontinuous Finite Element Method for Solving the Transport Problem with Anisotropic Scattering," Chinese J. Comput. Phys., 5, 325-338 (1988) (in Chinese)

[544] F. Shangwu, "Numerical Simulation of $14 \mathrm{MeV}$ Neutron Point Source in Finite Sphere," Chinese J. Comput. Phys., 6, 268-276 (1989) (in Chinese)

[545] S. Shiroya, M. Hayashi, K. Kanda, T. Shibata, W.L. Woodruff and J.E. Matos, "Analysis of the KUCA MEU Experiments Using the ANL Code System," Ann. Reports Research Reactor Inst., Kyota Univ., 16, 17-33 (1983)

[546] S. Shiroya, M. Hayashi, K. Kanda and T. Shibata, "Analysis on the KUCA MEU Experiments, (2). Boron Burnable-Poison Effect," Proc. Int. Mtg. on Reduced Enrichment for Research and Test Reactors, October 24, 1983, Tokai, Japan, JAERI-M-84-073, May 1984, pp 369-376

[547] S. Shiroya, M. Hayashi, K. Kanda, T. Shibata and T. Take, "Analysis of the Criticality Measurements in the Light-Water-Moderated Cores of the KUCA," Annual Report Research Reactors Inst. Kyota Univ., 18, 1-17 (1985)

[548] S. Shiroya, M. Hayashi, K. Kanda, and T. Shibata,"Analysis of Critical Experiments Using Medium-Enriched-Uranium Fuel in Kyoto University Critical Assembly (KUCA)," J. Nucl. Sci. Technol., 22, 507-520 (1985)

[549] C. Shuli, "RTDENT: A Finite Element Code for Two-Dimensional Neutron Transport," Hekexue Yu Gongcheng, 7, 120-131 (1987) (in Chinese)

[550] E. Shuttleworth, "FENDER: A Finite Element Code for the Solution of the Diffusion Equation in Shield Design Applications," Proc. Int. Seminar on Finite Element Methods in Radiation Physics, April 23-24, 1981, London Univ., London, UK, published in Ann. Nucl. Energy, 8, 597-607 (1981)

[551] E. Shuttleworth and S.J. Chucas, "Linked Monte Carlo and Finite Element Diffusion Methods for Reactor Shield Design," Proc. 6th Int. Conf. on Radiation Shielding 1, May 16, 1983, Tokyo, Japan, pp 180-187

[552] E. Shuttleworth and S.J. Chucas, "Development Work Currently Being Carried Out on the Finite-Element Diffusion Code FENDER," Workshop Seminar on Finite Element Multidimensional Diffusion Codes, Saclay, France, September 1516, 1983, published in Newsletter of the NEA Data Bank, No. 30, December 1983, pp 305-314

[553] P. Silvennoinen and J. Tuominen, "Curved Low Order Angular Elements in TwoDimensional Neutron Transport Problems," VTT-ENT-Pub-8, 1974, Valtion Teknillinen Tutkimuskus, Helsinki, Finland 
[554] E.G. Silver, "FEM2D: Program for Solving the Two-Dimensional Diffusion Equation by the Method of Finite Elements," ORNL-TR-2971, July 1974, Oak Ridge Nat. Lab., Oak Ridge, TN (Translation of IKE-4-25 by H.P. Franke and F.A.R. Schmidt)

[555] T. Sofu, E.L. Wachspress and H.L. Dodds, "A Nine-Point ADI Model Problem for Solution of the Diffusion Equation," Trans. Am. Nucl. Soc., 62, 298-299 (1990)

[556] B.A. Splawski, A.K. Ziver and J. Galliara, "Using Orthogonal Functions with a Finite Element Method for Approximating Even-Parity Neutron Flux in Slab Geometry," Nucl. Sci. Eng., 77, 351-354 (1981)

[557] L. Srinivasan, "X-Y-Z and R-Z Geometry Multigroup Diffusion Theory Calculation Using Variational Method," Atomkernenergie, 32, 175-177 (1978)

[558] J. Stepanek, J.W. Davidson, D. Dudziak and C.E. Higgs, "New Spatial and Angular Flux Approximations and Accelerations for the Finite Element Transport Code TRISM," Proc. Int. Seminar on Finite Element and Allied Methods for Reactor Physics and Shielding Calculations, September 18-20, 1985, London, England, published in Prog. Nucl. Energy, 18, 161-171 (1986)

[559] I.R. Suslov, "Transformation of the P1-Approximation Set of Equations into a Diffusion Equation Retaining Linearity of Boundary Conditions," FEI-827, 1978, Fiziko-Ehnergeticheskij Inst. (in Russian)

[560] R.H. Szilard and G.C. Pomraning, "A Modified Linear Discontinuous Spatial Discretization Method in Planar Geometry," Trans. Theory Stat. Phys., 18, 255-285 (1989)

[561] I. Tinka, "The State of Art of Most Frequently Used Methods for Solving the System of Multi-Group Diffusion Equations, II," Jaderna Energie, 22, 458-462 (1976) (in Czech)

[562] I. Tinka, "Current Trends in the Development of Methods for Solution of SpaceTime Kinetic Equations," Jad. Energ., 24, 304-310 (1978) (in Slovak)

[563] E.T. Tomlinson, J.C. Robinson and D.R. Vondy, "Solution of the Diffusion and $P_{1}$ Finite Element Equations by Iteration," Trans. Am. Nucl. Soc., 22, 248 (1975)

[564] E.T. Tomlinson, J.C. Robinson and D.R. Vondy, "Iterative Solution of the Diffusion and $P_{1}$ Finite Element Equations," ORNL/TM-5224, February 1976, Oak Ridge Nat. Lab., Oak Ridge, TN

[565] E.T. Tomlinson, Iterative Solution of the Diffusion and $P_{1}$ Finite Element Equations, PhD Dissertation, Univ. of Tennessee, Knoxville, TN, 1976

[566] E.T. Tomlinson and J.C. Robinson, "Solution of the Finite Element Diffusion and $P_{1}$ Equations by Iteration," Nucl. Sci. Eng., 63, 167-178 (1977) 
[567] A. Trkov, M. Najzer and L. Skerget, "Variant of Green's Function Nodal Method for Neutron Diffusion," J. Nucl. Sci. Technol., 27, 766-777 (1990)

[568] E.S. Tsapelkin, "Metod Galerkina dlya Diffuznykh Uravnenij," IAE-2474, 1975, Inst. Atomnoi Energii, Moscow, USSR (in Russian)

[569] M. Tsuchimoto, T. Honma, S. Tanaka and K. Miya, "Boundary Element Analysis of the Axisymmetric Neutron Diffusion Equation," Trans. Inst. Elect. Eng. Japan, Sec. $E, \mathbf{1 0 9}, 65-70$ (1989)

[570] S. Ukai, "Solution of Multi-Dimensional Neutron Transport Equation by Finite Element Method," J. Nucl. Sci. Technol., 9, 366-373 (1972)

[571] H. Utku and J.M. Christenson, "Stability of the TSM Finite Element Formulation of the Reactor Kinetics Equations," Trans. Am. Nucl. Soc., 64, 530 (1991)

[572] H. Utku and J.M. Christenson, "Condition Numbers of Finite Element Matrices for Some Typical Reactor Physics Problems," Trans. Am. Nucl. Soc., 65, 208 (1992)

[573] H. Utku and J.M. Christenson, "An Investigation of the Temporal Subdomain Method for Solving the Finite Element Formulation of the Space-Time Reactor Kinetics Equations," Nucl. Sci. Eng., 116, 55-66 (1994)

[574] J. Vacek, "Dual Variational Principles for an Elliptical Partial Differential Equation," Apl. Mat. (Czechoslovakia), 21, 5-27 (1976)

[575] J. Vacek, "Solution of the Neutron Diffusion Equation by the Finite Element Method. Part I. Theory and Methods," ZJE-201, 1977, Zavod Vystavba Jadernych Elektraren, Skoda, Czechoslovakia

[576] D. Verwaerde, "Transport Equation Solution by the Even Parity Method. Numerical Study of the Transport Evolution Equation in Two-Dimensional Lagrangian Geometry R-Z," CEA-N-2352, May 1983, CEA Centre d'Etudes de Limeil, 94 Villeneuve-Saint-Georges, France (in French)

[577] D. Verwaerde, "Les Approximations Deterministes de L'Equation du Transport des Neutrons," Chocs, 3, 37-44 (1991) (in French)

[578] M.R. Wagner, "Current Trends in Multidimensional Static Reactor Calculations," Proc. Conf. Computational Methods in Nuclear Engineering, April 15-17, 1975, Charleston, SC, Vol 2, pp I.1-I.23

[579] W.F. Walters and G.D. Miller, "Quadratic Finite Elements for X-Y and R-Z Geometries," Proc. Conf. Computational Methods in Nucl. Eng., April 15-17, 1975, Charleston, SC, Vol 2, pp I.39-I.51

[580] W.F. Walters and H. Komoriya, "An Energy-Dependent Finite Element Method for Few-Group Diffusion Equations," Trans. Am. Nucl. Soc., 21, 224-225 (1975) 
[581] W.F. Walters, "The Relation Between Finite Element Methods and Nodal Methods in Transport Theory," Proc. Int. Seminar on Finite Element and Applied Methods for Reactor Physics and Shielding Calculations, September 18-20, 1985, London, England, published in Prog. Nucl. Energy, 18, 21-26 (1986) (also LAUR-85-3276)

[582] J.T. Ward Jr., D.K. Trubey and H.R. Hendrickson, "Code Implementation of Partial-Range Angular Scattering Cross Sections: GAMMER and MORSE," Review of Multigroup Nuclear Cross-Section Processing (6 MeV), March 14, 1978, Oak Ridge, TN, ORNL/RSIC-41, pp 215-225

[583] T.A. Wareing, E.W. Larsen and M.L. Adams, "Diffusion Accelerated Discontinous Finite Element Schemes for the $S_{N}$ Equations in Slab and X,Y Geometries," Int. Topl. Mtg. Advances in Mathematics, Computations, and Reactor Physics, April 28-May 2, 1991, Pittsburgh, PA, Vol 3, pp 11.1 2-1-11.1 2-11

[584] T.A. Wareing, W.F. Walters, and J.E. Morel, "Diffusion-Accelerated Solution of the Two-Dimensional X-Y $S_{N}$ Equations with Linear-Bilinear Nodal Differencing," Nucl. Sci. Eng., 118, 122-126 (1994)

[585] T.A. Wareing, D.K. Parsons, and S. Pautz, "A Reactor Pressure Vessel Dosimetry Calculation Using ATTILA, An Unstructured Tetrahedral Mesh DiscreteOrdinates Code," Proc. Joint Int. Conf. Mathematical Methods and Supercomputing for Nuclear Applications, October 5-9, 1997, Saratoga Springs, NY, Vol 2, pp 1024-1030

[586] T.Y.C. Wei and K.F. Hansen, "Finite Element Method for Neutron Diffusion Problems in Hexagonal Geometry," C00-2262-7, June 1975, Mass. Inst. Tech., Cambridge, Mass.

[587] L. Weimin, Y. Banghua and X. Zhongsheng, "A Multigroup Finite Element Solution of the Neutron Transport Equation," Nucl. Power Eng., 11, 82-86 (1990) (in Chinese)

[588] J. Wepler and G. Memmert, "One-Dimensional Kinetic Model Calculations with Time-Discrete Finite Element Methods," TUBIK-32, September 1975, Technische Univ., Berlin, FRG (in German)

[589] J. Wepler, "Raumzeitabhangige Reaktordynamik auf der Basis eines 2D-FEMProgrammes," Atomkernenergie, 30, 95-101 (1977) (in German)

[590] R.C. Wheaton, Application of Phase-Space Finite Elements to the Neutron Transport Equation in Cylindrical Geometry, MS Thesis, AD-A-064209, Air Force Inst. Tech., Wright-Patterson AFB, Dayton, OH, 1978

[591] E.E. Wills, Finite Element Projection Method for the Solution of Particle Transport Problems with Anisotropic Scattering, PhD Dissertation, Univ. New Mexico, Albuquerque, NM, 1984 
[592] E. Wills, N. Roderick and P. McDaniel, "A Finite Element Projection Method for the Solution of Particle Transport Problems," Nucl. Sci. Eng., 93, 291-307 (1986)

[593] G. Wojtowicz and J.P. Holloway, "Variationally Derived Coarse Mesh Methods Using an Alternative Flux Representation," Proc. Int. Conf. Math. and Comp., Reactor Physics, and Env. Analyses, April 30-May 4, 1995, Portland, OR, Vol 1, pp 773-781

[594] J. Wood and M.M.R. Williams, "Recent Progress in the Application of the Finite Element Method to the Neutron Transport Equation," Prog. Nucl. Energy, 14, $21-40(1984)$

[595] J. Wood and C.R.E. de Oliveira, "A Multigroup Finite-Element Solution of the Neutron Transport Equation - I. X-Y Geometry," Ann. Nucl. Energy, 11, 229-243 (1984)

[596] J. Wood, "A Multigroup Finite-Element Solution of the Neutron Transport Equation - II. R-Z Geometry," Ann. Nucl. Energy, 12, 217-231 (1985)

[597] J. Wood, "Multigroup Anisotropic Scattering in the Finite Element Method," Int. Seminar on Finite Element and Allied Methods for Reactor Physics and Shielding Calculations, London, England, September 18-20, 1985, published in Prog. Nucl. Energy, 18, 91-100 (1986)

[598] J. Wood and M.M.R. Williams, "A Multigroup Finite-Element Solution of the Neutron Transport Equation - III. Anisotropy of Scattering," Ann. Nucl. Energy, 13, 479-491 (1986)

[599] H. Xing and E.H. Mund, "A Nonconforming Space-Angle Finite Element Approximation for Neutron Transport in Reactor Lattices," Proc. Int. Conf. Math. and Comp., Reactor Physics, and Env. Analyses, April 30-May 4, 1995, Portland, OR, Vol 1, pp 763-772

[600] S. Yang and A.F. Henry, "A Finite Element Synthesis Method," Nucl. Sci. Eng., 59, 63-67 (1976)

[601] C.E. Yehnert, Finite Element Solution of the Two-Dimensional Neutron Transport Equation, PhD Dissertation, Univ. Mich., Ann Arbor, MI, 1978

[602] I.L. Yong, K.K. Jong and D.S. Soo, "Finite Element Analysis of the Neutron Transport Equation in Spherical Geometry," J. Korean Nucl. Soc., 24, 319$328(1992)$

[603] K.J. Yoo, Application of the Finite Element Method to Neutronics Problems with Inhomogeneous Boundary Conditions, INIS-mf-7747, Thesis, Seoul Nat. Univ., Rep. of Korea, 1982 
[604] Y.C. Yuan, E.E. Lewis and W.F. Miller Jr., "Iterative Solution Methods for TwoDimensional Finite Element Approximations in Neutron Transport," Proc. Conf. Computational Methods in Nucl. Eng., April 15-17, 1975, Charleston, SC, Vol 2, pp III.85-III.100

[605] Y.C. Yuan and E.E. Lewis, "Two-Dimensional Multigroup Transport Calculations Using Phase-Space Finite Elements," Trans. Am. Nucl. Soc., 21, 227 (1975)

[606] Y.C. Yuan, Finite Element Solutions in Two-Dimensional Neutron Transport, PhD Dissertation, Northwestern Univ., Evanston, IL, 1976

[607] J.D. Zheng, "Error Estimation for Fully Discrete Finite Element Schemes for the Nonlinear Neutron Transport Equation," Comm. Appl. Math. Comput., 3, 6-15 (1989) (in Chinese)

[608] A.K. Ziver and A.J.H. Goddard, "A Finite Element Method for Multigroup Diffusion-Transport Problems in Two Dimensions," Proc. Int. Seminar on Finite Element Methods in Radiation Physics, April 23-24, 1981, London Univ., London, UK, published in Ann. Nucl. Energy, 8, 689-698 (1981)

[609] A.K. Ziver, A.J.H. Goddard and R.T. Ackroyd, "Considerations of Core Storage Arising from the Finite Element Analysis of Radiation Diffusion-Transport Benchmark Problems," Int. J. Numer. Methods Eng., 18, 1745-1764 (1982)

[610] A.K. Ziver, "An Introduction to FEED2 Two-Dimensional Finite Element Diffusion-Transport Code," Workshop Seminar on Finite Element Multidimensional Diffusion Codes, Saclay, France, September 15-16, 1983, published in Newsletter of the NEA Data Bank, No. 30, December 1983, pp 335-360 